\title{
Methane Production Rate during Anoxic Litter Decomposition Depends on Si Mass Fractions, Nutrient Stoichiometry, and Carbon Quality
}

\author{
Annkathrin Hömberg ${ }^{1, *}$, Klaus-Holger Knorr ${ }^{1} \mathbb{D}$ and Jörg Schaller ${ }^{2}[$ \\ 1 Ecohydrology \& Biogeochemistry Group, University of Münster, Heisenbergstraße 2, \\ 48149 Münster, Germany; kh.knorr@uni-muenster.de \\ 2 Leibniz Center for Agricultural Landscape Research (ZALF), 15374 Müncheberg, Germany; \\ Joerg.Schaller@zalf.de \\ * Correspondence: annkathrin.hoemberg@uni-muenster.de
}

Citation: Hömberg, A.; Knorr, K.-H.; Schaller, J. Methane Production Rate during Anoxic Litter Decomposition Depends on Si Mass Fractions, Nutrient Stoichiometry, and Carbon Quality. Plants 2021, 10, 618. https:// doi.org/10.3390/plants10040618

Academic Editor:

Barbara Hawrylak-Nowak

Received: 5 February 2021

Accepted: 19 March 2021

Published: 24 March 2021

Publisher's Note: MDPI stays neutral with regard to jurisdictional claims in published maps and institutional affiliations.

Copyright: (c) 2021 by the authors. Licensee MDPI, Basel, Switzerland. This article is an open access article distributed under the terms and conditions of the Creative Commons Attribution (CC BY) license (https:// creativecommons.org/licenses/by/ $4.0 /)$.

\begin{abstract}
While Si influences nutrient stoichiometry and decomposition of graminoid litter, it is still unclear how $\mathrm{Si}$ influences anoxic litter decomposition and $\mathrm{CH}_{4}$ formation in graminoid dominated fen peatlands. First, Eriophorum vaginatum plants were grown under different $\mathrm{Si}$ and $\mathrm{P}$ availabilities, then shoots and roots were characterized regarding their proportions of $\mathrm{C}, \mathrm{Si}, \mathrm{N}$ and $\mathrm{P}$ and regarding C quality. Subsequently the Eriophorum shoots were subjected to anoxic decomposition. We hypothesized; that (I) litter grown under high Si availability would show a higher Si but lower nutrient mass fractions and a lower share of recalcitrant carbon moieties; (II) high-Si litter would show higher $\mathrm{CH}_{4}$ and $\mathrm{CO}_{2}$ production rates during anoxic decomposition; (III) methanogenesis would occur earlier in less recalcitrant high-Si litter, compared to low-Si litter. We found a higher Si mass fraction that coincides with a general decrease in $\mathrm{C}$ and $\mathrm{N}$ mass fractions and decreased share of recalcitrant organic moieties. For high-Si litter, the $\mathrm{CH}_{4}$ production rate was higher, but there was no long-term influence on the $\mathrm{CO}_{2}$ production rate. More labile high-Si litter and a differential response in nutrient stoichiometry led to faster onset of methanogenesis. This may have important implications for our understanding of anaerobic carbon turnover in graminoid-rich fens.
\end{abstract}

Keywords: Silicon; Eriophorum vaginatum; peatland; organic matter degradation; carbon quality; biogenic silica

\section{Introduction}

During the postglacial period, northern peatlands began acting as great carbon $(\mathrm{C})$ sinks, now comprising a $C$ pool of $>500 \mathrm{Gt}$ of $\mathrm{C}$ [1], while covering only about $3 \%$ of the earth's land surface [2]. This $C$ accumulation occurs because once grown organic matter reaches the permanently waterlogged, anoxic parts of the profile, the catotelm, decomposition proceeds much more slowly than under oxic conditions of the acrotelm [3]. Despite the function as $\mathrm{C}$ sink, peatlands are also a source of greenhouse gasses such as carbon dioxide $\left(\mathrm{CO}_{2}\right)$ and methane $\left(\mathrm{CH}_{4}\right)$ [4]. In groundwater-fed peatlands, i.e., fens, the predominant vegetation is dwarf shrubs and graminoids, whereby graminoid roots primarily form the peat [5]. The aboveground biomass, which decomposes faster, is predominantly involved in respiration and methanogenesis and hence $\mathrm{CH}_{4}$ and $\mathrm{CO}_{2}$ production [5].

Decomposition of peat, which governs the release of dissolved organic carbon (DOC) and mineralization to $\mathrm{CO}_{2}$ and $\mathrm{CH}_{4}$, depends on the prevailing biogeochemical conditions [4], most importantly, the microbial activity, nutrient availability, electron acceptor availability, and the quality of the organic matter [4]. The nutrient availability in the peat influences decomposability [6] and the nutrient content in standing biomass [7,8], which after senescence undergoes decomposition and recycling. For a specific plant species, 
higher nutrient content can lead to lower amounts of microbially immobilized nitrogen (N) and phosphorus (P) and a faster release of $\mathrm{N}$ and $\mathrm{P}$ from decomposing litter [6]. This effect was amplified by higher litter production on plots with a higher $\mathrm{N}$ and $\mathrm{P}$ supply. However, across different plant species, a higher nutrient supply did not necessarily lead to higher decomposition rates [6].

One nutrient that has often been characterized as "beneficial" but "not essential", is silicon ( $\mathrm{Si}$ ). In wetland graminoids, Si may make up $>5 \%$ of the dry mass [9], but Si is still not considered "essential", because a lack of Si does not prevent plants from completing their life cycle nor is Si an essential plant metabolite $[9,10]$. Plants deprived of Si are often weaker, though they are hampered in their development and are prone to abiotic and biotic stresses [11]. Moreover, studies have repeatedly shown that Si accumulation in rice also influences the carbon quality in the litter [12-14]. Schaller et al. [11] found that litter with higher Si mass fractions had a lower share of cellulose, lignin, phenol, fat, wax, lipids and free organic acids, most of which are considered more recalcitrant compounds in plant litter [5]. As Si clearly influences living biomass and causes qualitative changes in the carbon compounds, the question arises as to whether the Si mass fraction, and thereby, its influence on $\mathrm{C}$ quality and nutrient stoichiometry, also affect the decomposition of litter from plants commonly found in fens.

The role of Si in plant litter decomposition was investigated by Schaller and Struyf [12] for Phragmites australis (Cav.) Trin. ex Steud rich and poor in Si. They based their experiment on the observation made by McClaugherty and Berg [8], who found that litter decay is influenced by the $\mathrm{N}$ and $\mathrm{P}$ content, the content of hardly degradable compounds like lignin and cellulose, and the phenol content. They found that a higher nutrient content and a lower content of more recalcitrant compounds and phenols increased decomposition rates [12]. Further, since Si influences the nutrient stoichiometry and, e.g., the share of phenols, as shown above, the authors proposed Si may directly or indirectly influence the decomposition of grasses. Contrary to the authors' expectations, Schaller and Struyf [12] found the highest rates of microbial decomposition under high Si availability. According to their interpretation, this was because high-Si conditions resulted in lower shares of cellulose and phenolics, and because silicic acid may have promoted fungal growth [13]. A higher Si mass fraction may go along with decreased nutrient mass fractions [12], but since the carbon quality is also changed under high Si uptake [11], the litter is probably more labile than litter with a lower Si mass fraction. Therefore, these effects may outweigh or interfere with each other and this must be further examined.

Under anoxic conditions and in absence of vegetation, an increase of $\mathrm{CO}_{2}$ and $\mathrm{CH}_{4}$ concentrations in peat pore waters were found, accompanied by a narrower $\mathrm{CO}_{2}: \mathrm{CH}_{4}$ ratio [14]. Mobilized $\mathrm{P}$ was suggested to have stimulated microbial degradation of DOC, leading to increased $\mathrm{CH}_{4}$ emissions. Si may have also exerted a direct influence on decomposition, though in this earlier study no mechanism was suggested. Nonetheless, the decreased mass fractions of $\mathrm{P}$ in graminoid litter due to the increased Si content promoted decomposition, as confirmed in other research [12].

Regardless of these uncertainties, most studies, with few exceptions, examined the effects in oxic environments. However, in wetlands and fens, decomposition in the anoxic peat is important, as this may control the formation of $\mathrm{CH}_{4}$ as an important greenhouse gas from anoxic wetland soils. However, we lack studies that specifically address anaerobic decomposition of litter differing in Si mass fractions. Therefore, we conducted a comprehensive study on; (1) the influence of increased Si availabilities in peat on the nutrient mass fractions and carbon quality in above- and belowground litter of Eriophorum vaginatum L.; and (2) on the differences in anaerobic decomposition of Eriophorum vaginatum aboveground litter differing in mass fractions of Si. In the first part of the study, we conducted a plant growth experiment with Eriophorum vaginatum under three levels of Si availability in the substrate. To decouple the effect of Si and the effect of P, we also integrated treatments with two different levels of phosphate fertilization. For the second part of the study, the 
litter of Eriophorum vaginatum that was grown under these conditions was subjected to decomposition in an incubation with six types of Eriophorum vaginatum aboveground litter.

For the Si and P fertilization experiment we hypothesized that; (I) litter grown under high Si availability in the substrate would have lower nutrient mass fractions and a lower share of recalcitrant compounds. For the decomposition experiment, we expected that, (II) litter with a high $\mathrm{Si}$ mass fraction would show higher $\mathrm{CH}_{4}$ and $\mathrm{CO}_{2}$ production rates upon anoxic incubation due to a lower share of recalcitrant organic matter. Moreover, we hypothesized that; (III) the onset of methanogenesis would be earlier for the decomposition of litter high in Si, compared to litter low in Si due to fast depletion of electron acceptors under high Si availability.

\section{Results}

\subsection{Part I-Characterization of the Plant Material \\ Stoichiometry}

Carex individuals produced very little biomass, especially aboveground. This did not visibly change with treatment. Eriophorum individuals were more vigorous in growth. Individuals that received more $\mathrm{P}$ with fertilization appeared more vital. By visual inspection, those plants that grew in the Si-rich substrate tended to develop more aboveground biomass, but as this was not the focus of our study, the exact biomass was not determined. Visual examination of the substrate during harvest revealed an infestation with root aphids (Rhizoecus ssp.) in the no-Si and the low-Si treatment, but not in the Si 10\% treatment. The root biomass was substantially higher in the Si 10\% treatment compared to the other treatments (Figure A1).

1. Eriophorum shoots

For detailed accounts of statistical data in brackets, we code the treatments as follows:

\begin{tabular}{|c|c|c|c|c|c|}
\hline Low-P Si 0\% & Low-P Si 1\% & $\begin{array}{l}\text { Low-P } \\
\text { Si10\% }\end{array}$ & $\begin{array}{c}\text { High-P Si } \\
0 \%\end{array}$ & $\begin{array}{c}\text { High-P Si } \\
1 \%\end{array}$ & $\begin{array}{c}\text { High-P } \\
\text { Si10\% }\end{array}$ \\
\hline ' 1 ' & '2' & '3' & ${ }^{\prime} \mathrm{I}^{\prime}$ & ‘II' & ‘III' \\
\hline
\end{tabular}

We found lower C mass fractions in the shoots of Eriophorum for those treatments that had increased amounts of $\mathrm{Si}$ in the substrate (Figure 1). The difference in the C mass fraction between the "low-P Si 0\%" and "low-P Si 10\%" treatments was significant ( $t$-test, $p$-value $=0.03)$. There was no difference in the $C$ mass fractions between the low-P and high-P treatment groups. The mass fractions of $C$ varied between $41 \%$ and $49 \%$ of the dry mass. Compared to the Carex shoots, the C mass fraction of Eriophorum was significantly higher (Figure 2).

The mass fraction of Si increased with increasing Si addition to the substrate (Figure 1). The differences between the different Si treatments were significant (All: $t$-test: 1 and 2: $p=1.141 \times 10^{-4} / 1$ and 3: $p=8.833 \times 10^{-4} / 2$ and 3: $p=4.621 \times 10^{-4} / \mathrm{I}$ and II: $p=1.868 \times$ 10 $0^{-8} /$ I \& III: $p=2.813 \times 10^{-6} / \mathrm{II} \&$ III: $\left.p=4.765 \times 10^{-6}\right)$. Yet, there was no difference in the Si mass fraction of the shoots, between the low-P and high-P treatment groups. Carex shoots had a tendentially higher Si content compared to Eriophorum shoots, especially in the low-P treatment (not significant; Figure A2).

The mass fraction of $\mathrm{N}$ in the $\mathrm{Si} 0 \%$ shoots was significantly higher compared with those treatments with Si added to the substrate (All: $t$-test: $1 \& 2: p=0.006 / 1 \& 3: p=5.419 \times$ $10^{-4} /$ I\&II: $p=3.669 \times 10^{-3} /$ I\&III: $p=1.399 \times 10^{-3}$ ) (Figure 1). The difference between Si $1 \%$ and $\mathrm{Si} 10 \%$ was not significant, but the decreasing trend was apparent. Moreover, the high-P treatment group here had a significantly lower $\mathrm{N}$ mass fraction, compared to the low-P treatment group ( $t$-test, $p$-value $=0.004)$. The $\mathrm{N}$ mass fraction was higher for Carex compared to Eriophorum in most treatments (Figure A2). 
There was more $\mathrm{P}$ in the shoots that received higher $\mathrm{P}$ fertilization $(t$-test, $p$-value $=0.009)$ compared to low-P (Figure 1). We found that there was no clear trend in the $\mathrm{P}$ mass fraction regarding the different $\mathrm{Si}$ additions, except for a significantly ("low-P Si 1\%") or insignificantly ("high-P Si 1\%") lower value compared to the Si $0 \%$ and the Si 10\% treatments.

The C/N ratio was significantly higher for those treatments that had higher Si availability in the substrate compared to the Si 0\% treatment (All: $t$-test: $1 \& 2: p=6.52 \times$ $10^{-4} / 1 \& 3: p=1.913 \times 10^{-3} /$ I\&II: $p=3.684 \times 10^{-3} /$ I\&III: $p=1.55 \times 10^{-3}$ ) (Figure 1). This was due to the decreasing $C$ mass fraction with increasing Si availability and the differently changing $\mathrm{N}$ mass fraction. The $\mathrm{C} / \mathrm{N}$ ratio of Carex shoots was significantly lower than that of Eriophorum (Figure A2).

The $\mathrm{N} / \mathrm{P}$ ratio had a decreasing trend with increasing Si availability, albeit mostly not significant (Figure 1). The Si $0 \%$ and the Si 10\% treatments differed in N/P in both $\mathrm{P}$ treatment groups, respectively. The $\mathrm{N} / \mathrm{P}$ ratio was significantly lower for the high-P treatment group, compared to the low-P treatment group ( $t$-test, $p$-value $=0.003$ ).

Eriophorum shoots of the Si $0 \%$ treatment showed the highest absorption signal compared to the other treatments around wavenumber 3380, indicating phenolic structures and around wavenumbers 1630, 2850 and 2920, indicating aliphatic structures (Table 1). Moreover, a higher share of lignin (wavenumber 1630) was found. The treatments with Si $1 \%$ showed lower absorption than the Si 0\% treatment and the Si 10\% treatment showed even lower absorptions. The high P treatment showed a slightly lower signal respectively, especially around wavenumber 3380. The fourier transform infrared spectroscopy (FTIR) ratios (Table A3) of the Eriophorum shoot material showed comparable patters. All ratios showed decreasing values with the increasing Si mass fraction in the leaves in both, the low and high $\mathrm{P}$ treatment group.

Table 1. Wavenumbers used for FTIR ratios, their indication and references.

\begin{tabular}{|c|c|c|}
\hline Wavelength or Ratio & Indicative of & Reference \\
\hline 1090 & Polysaccharides & Broder et al. [15] \\
\hline $1350 / 1090$ & $\begin{array}{l}\text { symmetric }-\mathrm{COO}^{-} \text {stretch and / or } \\
-\mathrm{CH} \text { bending of aliphatic structures } \\
\text { Aromatic } \mathrm{C}=\mathrm{C}^{-} \text {and } \mathrm{COO}^{-} / /\end{array}$ & Niemeyer et al. [16] \\
\hline $1630 / 1090$ & $\begin{array}{l}\text { aromatics and aromatic or aliphatic } \\
\text { carboxylates }\end{array}$ & Broder et al. [15] \\
\hline $1720 / 1090$ & Aromatic $\mathrm{C}=\mathrm{C}$ or $\mathrm{C}=\mathrm{O}$ of amides & Broder et al. [15] \\
\hline $2850 / 1090$ & $\begin{array}{l}\text { Symmetric } \mathrm{CH} 2 \text {, aliphatic structures, } \\
\text { waxes, and lipids }\end{array}$ & $\begin{array}{c}\text { Schaller et al. [11] } \\
\text { Agethen and Knorr [7] }\end{array}$ \\
\hline $2920 / 1090$ & $\begin{array}{l}\text { Antisymmetric } \mathrm{CH} 2 \text {, waxes and } \\
\text { lipids }\end{array}$ & $\begin{array}{l}\text { Agethen and Knorr [7] } \\
\text { Schaller et al. [11] }\end{array}$ \\
\hline $3380 / 1090$ & $\mathrm{OH}^{-}$stretch of phenolic structures & Niemeyer et al. [16] \\
\hline
\end{tabular}



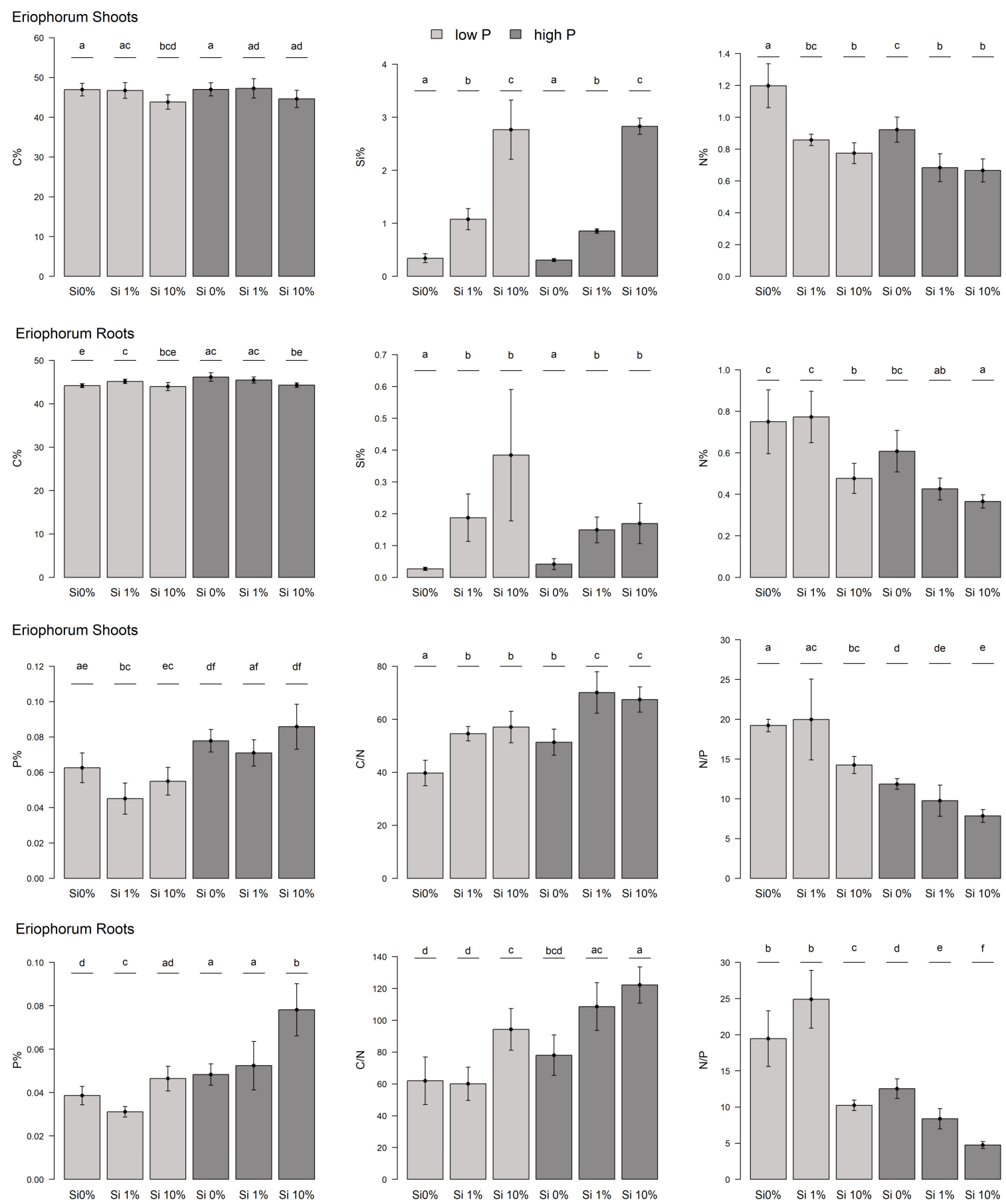

Figure 1. Element mass fractions and stoichiometry of Eriophorum aboveground and belowground biomass. Mass fractions of $\mathrm{C}, \mathrm{Si}, \mathrm{N}$ as well as $\mathrm{P}$ and the $\mathrm{C} / \mathrm{N}$ and $\mathrm{N} / \mathrm{P}$ ratios are displayed. Low-P fertilized plants: light gray, high-P fertilized plants: dark gray. Different letters give significant differences between the treatments $(\alpha=0.05)$. 

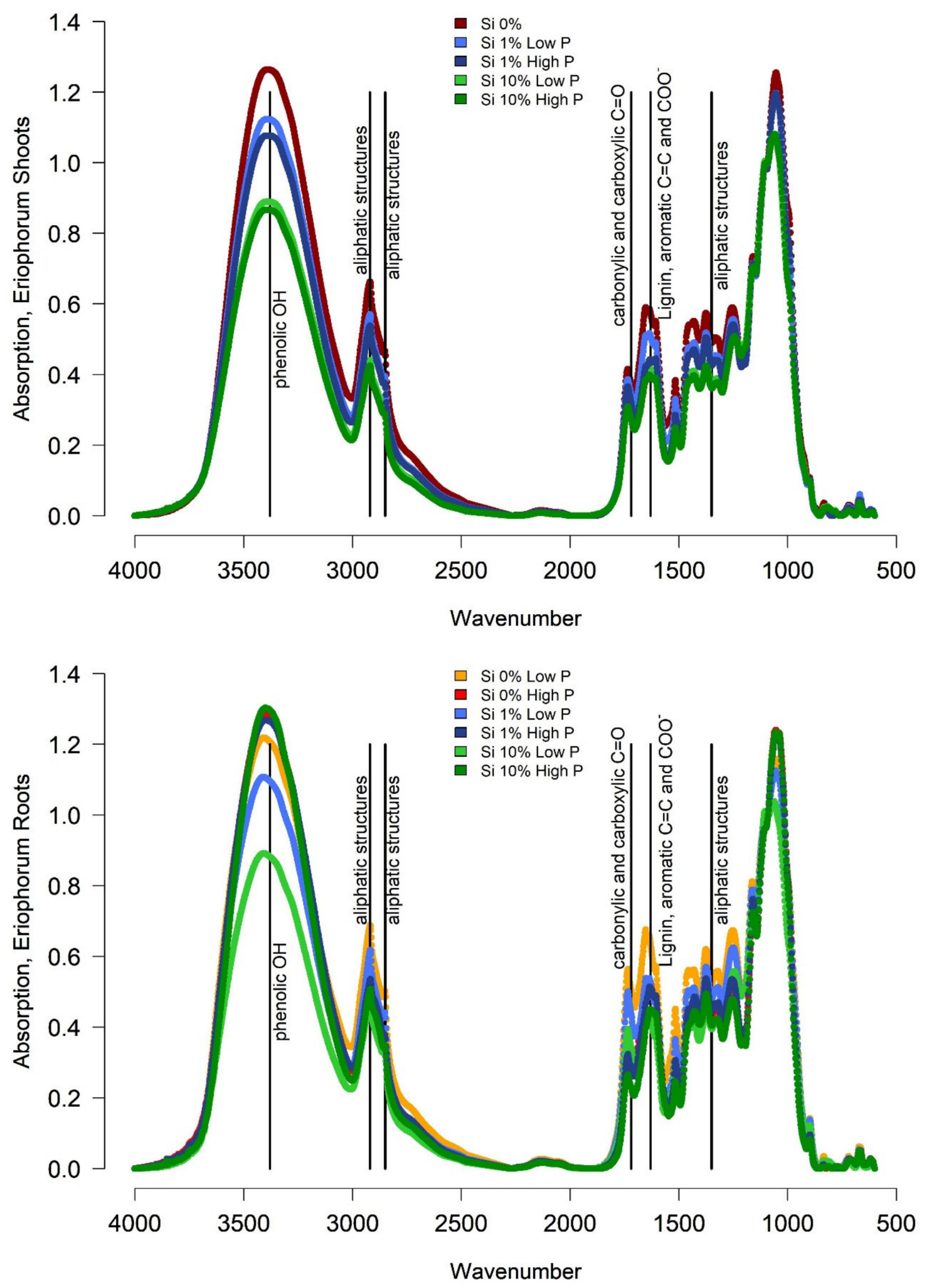

Figure 2. FTIR Spectra of Eriophorum shoots and roots before the incubation. For Eriophorum shoots only a mixed sample of the Si 0\% low and Si 0\% high P treatment is available (divergent color code: Si 0\%: dark red). 


\section{Eriophorum roots}

The roots of Eriophorum (Figure 1) showed similar patterns to its aboveground biomass. Generally, the mass fraction of $\mathrm{C}$ decreased slightly with increasing Si availability. This difference in C was significant comparing "high-P Si 0\%" and "high-P Si 10\%" ( $t$-test, $\left.p=9.673 \times 10^{-3}\right)$. In the low-P treatment group, the Si $1 \%$ treatment was an exception, with the $\mathrm{C}$ mass fraction significantly higher compared to the $\mathrm{Si} 0 \%$ treatment $(t$-test, $p=0.021)$. No general difference was found from the mass fraction of $C$ in the Eriophorum shoots.

The Si mass fraction was much lower $(0.02 \%$ to $0.64 \%)$ in the Eriophorum roots than in the shoots of Eriophorum, though (0.27\% to 3.81\%) (Figure 1). The Si 1\% and Si 10\% treatments had, as expected, significantly more Si than the Si $0 \%$ treatments (welch-test: 1\&2: $p=0.012 /$ welch-test: $1 \& 3: p=0.026 / t$-test: I\&II: $p=1.186 \times 10^{-3} /$ welch-test: I\&III: $p=0.014)$.

In relation to $\mathrm{N}$, there was no significant difference between the "low-P Si $0 \%$ " and the "low-P Si 1\%" treatment, whereas the "low-P Si 10\%" treatment displayed a significantly lower mass fraction of $\mathrm{N}\left(1 \& 3\right.$ : $t$-test, $p=0.123 / 2 \& 3$ : $t$-test, $\left.p=3.295 \times 10^{-3}\right)$ (Figure 1). For the high-P treatment this holds true comparing the "high-P Si 0\%" and the "high-P Si 10\%" treatment $\left(t\right.$-test, $\left.p=1.706 \times 10^{-3}\right)$. Besides the "low-P Si 1\%" treatment, all treatments had a significantly lower $\mathrm{N}$ mass fraction in the Eriophorum roots than in the shoots (Figure 1).

For the Eriophorum roots, the mass fraction of $\mathrm{P}$ was lower for the $\mathrm{Si} 0 \%$ and the $\mathrm{Si} 1 \%$ treatments of both $P$ fertilization variants, compared to the shoots (Figure 1). The P mass fraction generally increased slightly with increasing $P$ availability.

Due to the significant effect of $\mathrm{Si}$ availability on the N mass fraction in the $\mathrm{Si} 10 \%$ treatment (see above), the $\mathrm{C} / \mathrm{N}$ ratio was significantly higher for the "low-P Si 10\%" treatments compared to the "low-P Si 0\%" and the "low-P Si 1\%" treatment (1\&3: $t$-test, $p=0.012 / 2 \& 3: t$-test, $\left.p=3.511 \times 10^{-3}\right)$ (Figure 1). The difference in the $\mathrm{C} / \mathrm{N}$ ratio between the "high-P Si0\%" and the "high-P Si10\%" treatments was also significant (I\&III: $t$-test, $\left.p=8.474 \times 10^{-4}\right)$.

The N/P ratio displayed large differences between the treatments, which was due to the described patterns in $\mathrm{N}$ and $\mathrm{P}$ (Figure 1). The ratio decreased with increasing $\mathrm{Si}$ availability and was also lower for the high-P treatment group due to the low $\mathrm{N}$ mass fraction.

The roots of Eriophorum displayed slightly higher FTIR ratios than Eriophorum shoots (Table A3). The differences between Si treatments were much less clear (Figure 2). Instead, there was a difference in the absorption between the low-P and the high-P treatments, the latter always showed a higher absorption at wavenumbers, which was indicative of more refractory compounds. This difference was especially pronounced in the "Si 10\%" treatment.

\subsection{Decomposition of the Plant Material}

\subsection{1. $\mathrm{CO}_{2}$ and $\mathrm{CH}_{4}$ Production Rates of Eriophorum Shoot Litter}

Within the first 11 days, the $\mathrm{CO}_{2}$ production rate was significantly higher in the $\mathrm{Si} \%$ treatments compared to the $\mathrm{Si} 1 \%$ treatment in the low-P treatment group and compared to the Si 1\% and Si 10\% in the high-P treatment group (all: welch-test: $1 \& 2: p=0.022 /$ I\&II: $p=0.020 /$ I\&III: $p=0.013$ ). The $\mathrm{CO}_{2}$ production of the control (peat only) was significantly smaller than production rates of all other incubations with shoot biomass (Figure 3).

In the following phases of the long-term incubation, i.e., day 11-25, day 25-51 and day 51-72, there were no significant differences in the $\mathrm{CO}_{2}$ production rates between the treatments, except the control without litter, producing $\mathrm{CO}_{2}$ at a significantly lower rate. During the incubation, the mean $\mathrm{CO}_{2}$ production rate (except the control) decreased substantially. From day $72-100$, the $\mathrm{CO}_{2}$ production stagnated at a very low level. 
The $\mathrm{CH}_{4}$ production (Figure 3) only began after about 50 days of incubation. The variance of this time lag was large, as some bottles produced $\mathrm{CH}_{4}$ early (specially from the Si $10 \%$ group) and others late. Due to the number of replicates (5) this led to hardly any significant differences. Nevertheless, the tendency was apparent: A higher Si mass fraction in the shoots led to higher $\mathrm{CH}_{4}$ production rates in the incubation. This held true for both $\mathrm{P}$ treatment groups and both displayed $\mathrm{CH}_{4}$ production only in the later phase of the 100 days incubation during day $51-72$ and day $72-100$. At the end, $\mathrm{CH}_{4}$ production was on average 10 -fold larger in the high-Si treatments than during day $51-72$. The Si $0 \%$ treatment however, showed hardly any $\mathrm{CH}_{4}$ production throughout the 100-day incubation.
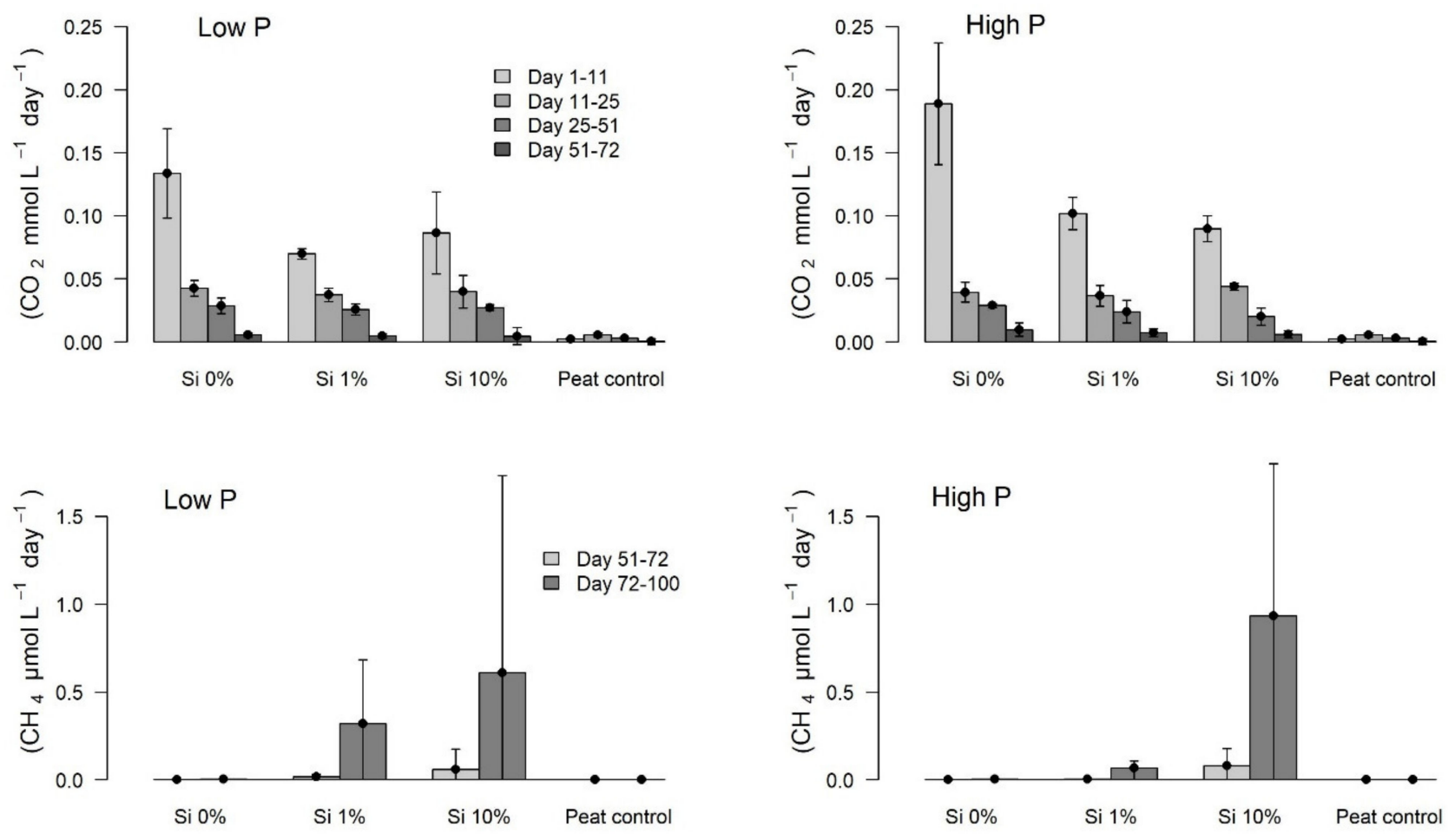

Figure 3. $\mathrm{CO}_{2}$ (top) and $\mathrm{CH}_{4}$ (bottom) production rates during the initial phase (day 1-11) and the long-term incubation period of Eriophorum shoots. Methanogenesis only started after 50 days, therefore the time before is not displayed in the graphs at the bottom.

2.2.2. Litter Quality and $C$ and $N$ Mass Fractions of Eriophorum Shoots after Incubation

The shoots of Eriophorum after incubation differed in their FTIR signal to the shoots before the incubation (Figure 4). 

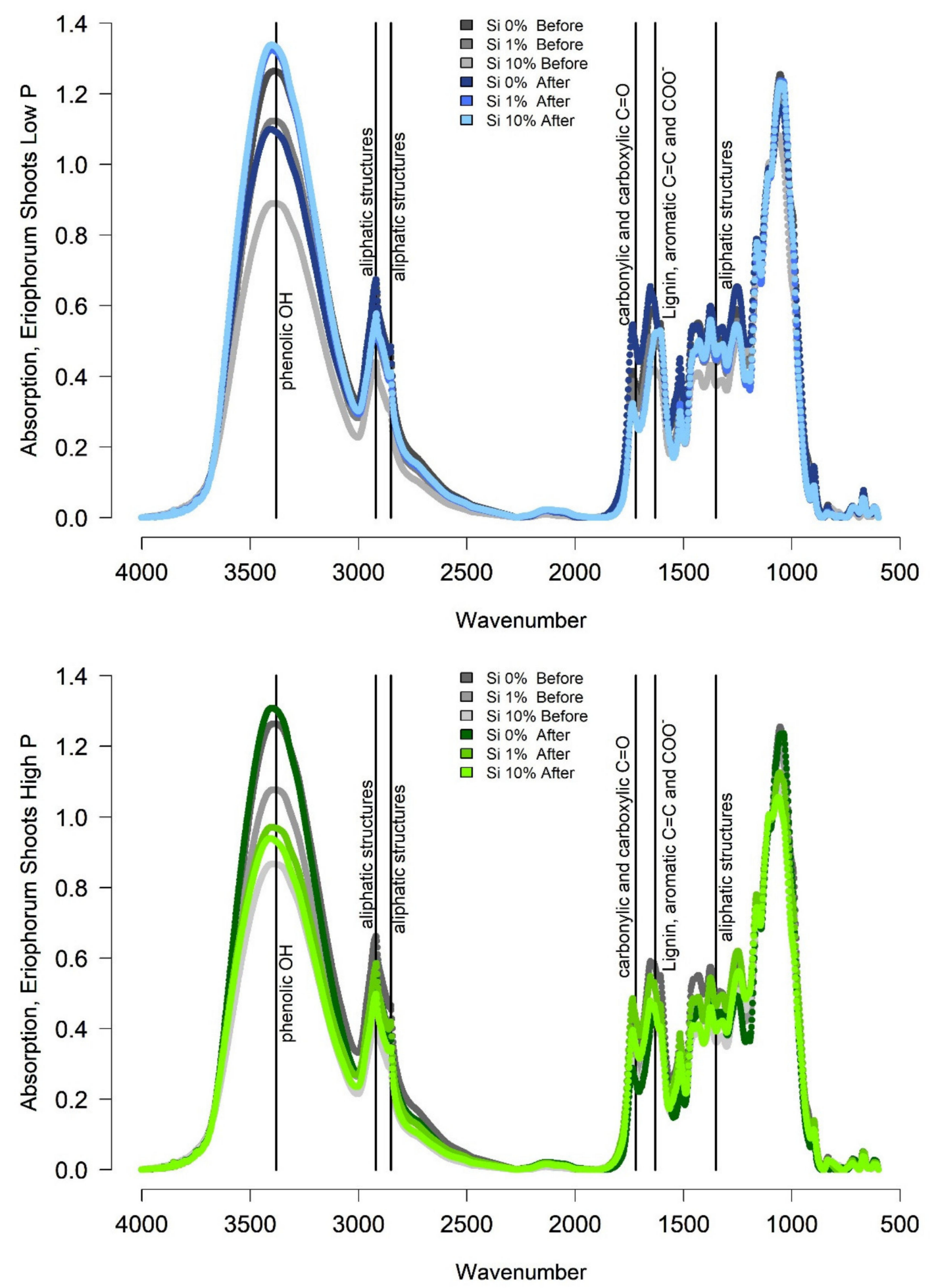

Figure 4. FTIR Spectra of Eriophorum shoots after the incubation in blue (low-P treatments) and green (high-P treatments). For the Si $0 \%$ both, the low and the high P spectrum, are the same, since no individual samples were available. Correspondent spectra from before the incubation are given in gray for orientation. The brightness of colors is according to the Si treatment.

The absorption spectra, especially around wavenumber 3380, were higher for the "low-P Si 1\%" and the "low-P Si 10\%" treatment after the incubation compared to before due to a relative increase in the share of recalcitrant material (Figure 4). The "Si $0 \%$ low- $\mathrm{P}^{\prime \prime}$ spectrum rather showed a lower absorption around wavenumber 3380 after the incubation. For the high-P treatment group, the Si $0 \%$ and the Si 10\% treatment showed 
higher absorption around wavenumber 3380, only the Si 1\% spectrum showed lower absorption after the incubation compared to before the incubation. Meanwhile, most ratios increased or decreased in the same manner, displaying a higher share of recalcitrant material after the incubation for the "low-P Si 1\%", the "low-P Si 10\%" and the "high-P Si $0 \%$ " and the "high-P Si 10\%" treatment.

The C mass fraction of Eriophorum shoots generally decreased over the incubation period. However, the "low-P Si 10\%" treatment showed an increasing C mass fraction over the incubation period. The $\mathrm{N}$ mass fraction increased in the $\mathrm{Si}$ addition treatments of the low-P group and in the "high-P Si 0\%" treatment and did not differ for the other treatments. The $\mathrm{C} / \mathrm{N}$ ratio (Figure 5) generally decreased over the incubation time, as expected, but showing no significant difference for the "low-P Si 0\%" and the "high-P Si 1\%" treatment.

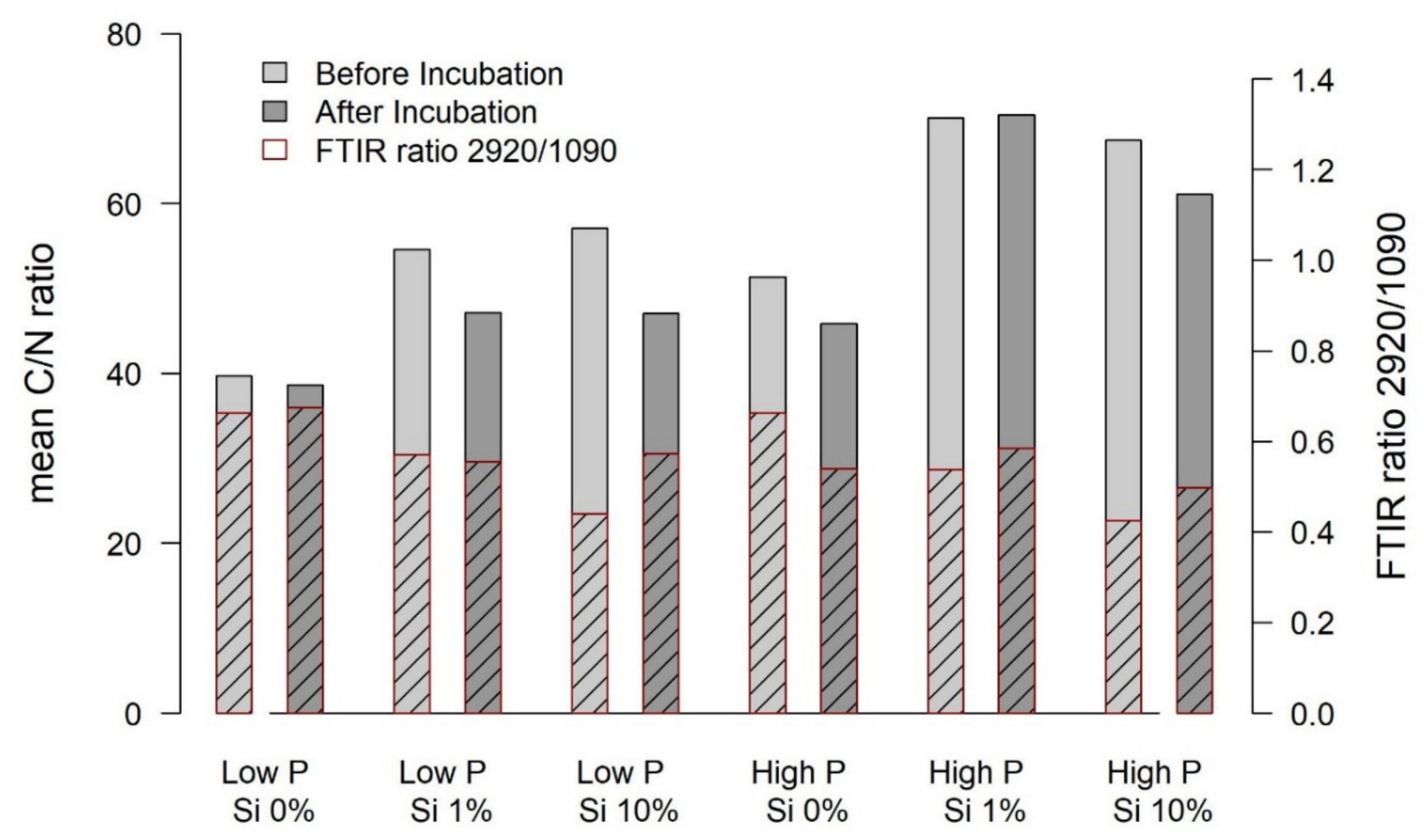

Figure 5. Mean values of the $\mathrm{C} / \mathrm{N}$ ratios of biomass of Eriophorum shoots before and after the incubation (left $y$-axis). The hatched area denotes the FTIR ratio 2920/1090 (indicative for aliphatic structures; waxes and lipids) before and after the incubation-referring to the right axis.

\subsubsection{Nutrient Leaching into the Water Phase}

The concentrations of dissolved Si, P, TOC, and Fe in the water, at the beginning and at the end of the incubation with Eriophorum shoots, displayed significant differences (Figure 6) (for detailed statistics see Table A4). The concentrations of Fe and Si were significantly higher at the end of the incubation for all treatments.

In comparing the concentration differences of $\mathrm{Si}, \mathrm{TOC}, \mathrm{P}$ and $\mathrm{Fe}$ at the beginning and the end of the incubation, significantly higher (Figure 6, Table A4) differences were found in the Si concentrations of the "Si 10\%" treatments than for the other treatments. The $\mathrm{P}$ treatment did not influence the Si concentration increase. Concentrations in Fe increased more strongly in the low-P compared to high $\mathrm{P}$ treatments.

The concentration of TOC and P decreased over time; TOC concentrations were significantly lower (Figure 6, Table A4) in each treatment group, and $\mathrm{P}$ concentrations were lower in each treatment except the "low-P Si 0\%" treatment group. In the high-P treatments, the $\mathrm{P}$ concentration, and the decrease in concentration during the experiment in the water phase was significantly higher than in the low-P treatments (Figure 6, Table A4). The decrease in P concentration during the experiment was larger for the high-Si treatments. 

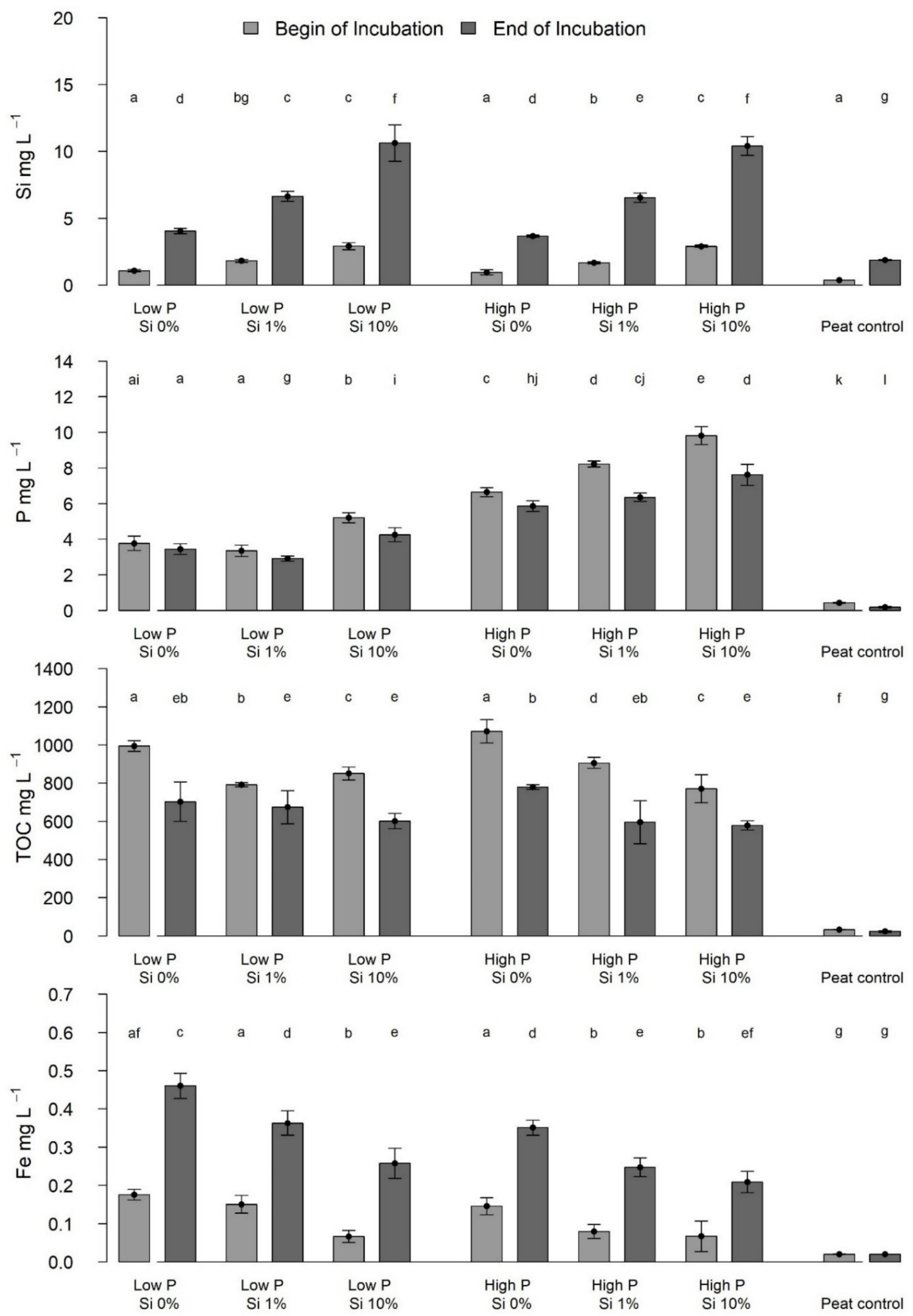

Figure 6. Concentrations of dissolved $\mathrm{Si}, \mathrm{P}, \mathrm{TOC}$ and $\mathrm{Fe}$ in $\mathrm{mg} \mathrm{L}^{-1}$ in the water phase after 11 days (light grey bars) and after 100 days (dark gray bars) at the begin and end of Eriophorum shoot incubation. Lower case letters indicate significant differences $(p<0.05)$. 


\section{Discussion}

\subsection{Characterization}

Our study revealed some general differences between the investigated species concerning Si uptake and its effects on other nutrients stoichiometry. Carex shoots had a higher Si mass fraction $(0.8-5.6 \% \mathrm{dm})$ than Eriophorum shoots $(0.3-3.8 \% \mathrm{dm})$, and Carex shoots accumulated more Si especially in the $1 \%$ Si treatment, which reached an Si mass fraction in the shoots as high as in the $10 \% \mathrm{Si}$ treatment. Both values were on the same order of magnitude as for rice straw investigated by Klotzbücher et al. [17] (3.7 $\pm 1.2 \%$ standard deviation) and coincide with Si contents reported for graminoids [18,19]. Compared to our field survey data on Eriophorum Si mass fractions, the 0\% Si treatment had an Si mass fraction just slightly below these field data (0.5-0.6\% Si in Eriophorum shoots from the field).

Carex had a generally higher $\mathrm{N}$ mass fraction compared to Eriophorum in the shoots and roots. Klotzbücher et al. [17] found the Si content to be severalfold higher than the $\mathrm{N}$ and $\mathrm{P}$ contents of the rice straw they investigated. Here, we only found this to be true for the shoots of both species that were amended with at least $1 \% \mathrm{Si}$ in the substrate. The roots always contained less $\mathrm{Si}$ than $\mathrm{N}$ on a mass basis. Eriophorum showed decreasing mass fractions of $\mathrm{N}$ with increasing $\mathrm{P}$ availability and Carex displayed a higher $\mathrm{N}$ mass fraction under increasing $\mathrm{P}$ availability. Carex accumulated much more $\mathrm{P}$ compared to Eriophorum when high amounts of $\mathrm{P}$ were available. Therefore, the $\mathrm{N} / \mathrm{P}$ and the $\mathrm{C} / \mathrm{N}$ ratio differed between both species. Carex generally had a narrower $\mathrm{C} / \mathrm{N}$ ratio compared to Eriophorum, and for Carex the N/P ratio showed stronger dependence on the P level.

Based on reported observations [11,17], we hypothesized; that (I) litter grown under high Si availability in the substrate would show lower $\mathrm{N}$ and $\mathrm{P}$ mass fractions and a lower share of phenols, aliphatic groups, carboxylic groups, and waxes. Concerning Eriophorum shoots, this hypothesis was verified for $\mathrm{N}$, but not for $\mathrm{P}$. The $\mathrm{C}$ mass fraction also decreased with increasing $\mathrm{Si}$ content of the shoots. Both findings align with the findings of some studies $[19,20]$, but contrast with others in which $\mathrm{N}$ uptake correlated positively with $\mathrm{Si}$ uptake for poaceae.

However, Schaller et al. [20], found $\mathrm{N}$ did not correlate with Si in rice straw. Also, we found that the P mass fraction did not depend on Si content in Eriophorum shoots, coinciding with the findings of Klotzbücher et al. [17]. Eriophorum roots showed a generally similar pattern, where Si had a significant influence on the $\mathrm{N}$ mass fraction, especially in the high $\mathrm{Si}$ treatment. When the Si mass fraction was higher, the roots' $\mathrm{C} / \mathrm{N}$ ratio was consequently higher and the N/P ratio lower. To our knowledge, no other study has analyzed the influence of $\mathrm{Si}$ on root stoichiometry of wetland graminoids, even though root biomass is an important part of total biomass and is responsible for most peat formation in fen peatlands [5] and, thus, it should be investigated individually [21].

FTIR ratios only allow interpretation of relative shares of compounds, not absolute contents (Table 1). Nevertheless, the original Eriophorum shoots showed decreasing FTIR ratios with an increasing Si mass fraction of the shoots, for both, the "low- $\mathrm{P}^{\text {" and the }}$ "high-P" treatment group (Table A3). The share of recalcitrant material, hence, decreases with increasing Si content. In line with our findings, also others [11,17] found a negative correlation between Si content and lignin content of rice straw. Schoelynck et al. [22] used extraction methods to determine the cellulose and lignin content of wetland plants. In their study, for wetland graminoids like Phragmites australis and Glyceria maxima, they found no relationship between lignin and Si content in the plants. Schaller et al. [23], however, found decreasing cellulose/silicon and lignin/silicon ratios in Phragmites australis with increasing Si availability when using extraction techniques. Here, the roots of Eriophorum showed decreasing FTIR ratios with an increasing Si mass fraction of the shoots for the "low- $\mathrm{P}$ " treatment group. For the "high- $\mathrm{P}$ " treatment group only small differences could be observed, while a decreasing trend with an increasing Si mass fraction was still discernible.

This change of compound share under higher availability of $\mathrm{Si}$ was expected since graminoids can replace structures like lignin, aromatic, carbonylic, carboxylic and aliphatic structures by precipitation of $\mathrm{Si}$, as Schaller et al. [11] demonstrated for rice plants. These 
authors also found a relative reduction in the share of wax and lipids, free organic acids and lignin with increasing Si content $[11,23]$. The effect of Si on Eriophorum shoot structural $\mathrm{C}$ composition was overall larger for shoots than for roots. The roots only showed a strong change in structural $\mathrm{C}$ composition in the low-P treatment group. Si is primarily transported to the shoots instead of the roots [24], which might be a reason for the clearer $\mathrm{Si}$ effect of structural C composition in the shoots compared to the roots.

\subsection{Decomposition}

Upon investigating the decomposition of the Eriophorum shoots, we hypothesized (II) that litter with a high $\mathrm{Si}$ mass fraction would show higher $\mathrm{CH}_{4}$ and $\mathrm{CO}_{2}$ production rates due to lower shares of recalcitrant organic matter, such as phenols and aliphatic groups. To this end, we analyzed the time course of $\mathrm{CO}_{2}$ and $\mathrm{CH}_{4}$ production rates. Only during the initial phase (day 1-11), did Si seem to increase the $\mathrm{CO}_{2}$ production rate. In relation to the entire incubation (1-72), there was more $\mathrm{CO}_{2}$ produced in the $\mathrm{Si} \%$ treatments, compared to the other treatments. This difference was, thus, primarily due to differences in the initial phase. This finding contradicts the findings of Schaller and Struyf [12], who found higher decay rates of litter with increasing Si content of the litter, even though our experiment also had a lower share of phenols in the material.

The result of our experiment contradicted our expectation: Higher $\mathrm{CO}_{2}$ production was found in treatments with a very low $\mathrm{Si}$ mass fraction, and lower $\mathrm{CO}_{2}$ production rates were found in treatments with shoots which had a high Si mass fraction. In the long-term incubation phase, there was no significant difference between the treatments, though, except the peat control treatment, which showed much lower rates than the treatments with litter addition. In accordance with Gao et al. [25], $\mathrm{CO}_{2}$ production was higher in the beginning of the experiment compared to the end of the experiment. According to Hömberg et al. [26], we expected increased $\mathrm{CO}_{2}$ production in the treatments that had received Si-rich plant material. The differences between both experiments were either due to the different ways in which $\mathrm{Si}$ was added - either as inorganic salt $\left(\mathrm{Na}_{2} \mathrm{O}_{3} \mathrm{Si}\right)$ or as a plant bound biogenic Si (this study). Another possibility would be that this difference was caused by Si interacting with other plant constituents like N, P, S, and the C quality, yet we cannot draw conclusions from data available here.

The differences in $\mathrm{CH}_{4}$ production rates agreed, to a large extent, with our hypothesis. We expected greater $\mathrm{CH}_{4}$ production in the high-Si treatment compared to the no-Si treatment. These differences, while not significant due to high variability, showed clear trends. Reithmaier et al. [14] also found increased $\mathrm{CH}_{4}$ concentrations in their field study, where peat was amended with amorphous Si. Our finding is also in accordance with the results from Hömberg et al. [26], even though both experiments did not use Si bound in biomass but used amorphous $\mathrm{SiO}_{2}$ or $\mathrm{Na}_{2} \mathrm{O}_{3} \mathrm{Si}$ added as inorganic fertilizer. The low $\mathrm{CH}_{4}$ production during the initial phase of the incubation coincides with a high share of phenols in the low-Si shoot material, especially in the low-P treatments. High concentrations of phenols have been shown to inhibit methanogenic processes $[27,28]$.

The water phase showed an increase in Si and Fe concentrations over the time of the incubation, whereas the concentrations of TOC and P decreased. The increase in Si may be explained by progressive leaching of Si from the shoot material during decomposition. Like Schaller and Struyf [12], we found that from material with higher initial Si mass fractions, more Si was leached. Yet, the increase in leached Si was not proportional to the increase in the mass fraction of $\mathrm{Si}$, which was probably due to the higher $\mathrm{CO}_{2}$ production and thus $\mathrm{C}$ mineralization rate in the "Si $0 \%$ " treatment, potentially releasing comparatively more $\mathrm{Si}$. The decrease in DOC, was pronounced for the "Si $0 \%$ " treatment, whereas the decrease in dissolved P was most intense for the "Si 10\%" treatment. The decrease in DOC, especially from those shoots with a low Si mass fraction, can be attributed to the high degradability of C leached from Eriophorum shoots [29] and the correspondingly higher $\mathrm{CO}_{2}$ production rate. The decrease in $\mathrm{P}$ concentration was pronounced for the shoots with a high Si mass fraction, even though this was not due to the P mass fraction in the shoots, which showed 
no differences. Probably, there was higher P leaching from those shoots that contained more Si. This could be due to extremely fast release of Si from graminoid shoots [30], and thereby, release of easily utilizable P structures [31-33]. It may also be explained by the competition of silicic acid and P regarding their binding to soil particles [26,32]. The binding affinity of silicic acid to soil particles is depending on its speciation. Polysilicic acid, which is the predominant species during dissolution of amorphous $\mathrm{Si}$, shows particularly high binding affinity [34]. Schaller and Struyf [12] found the water phase of their high-Si incubation to contain lower concentrations of P during the experiment, which was not the case in our experiment (higher P concentrations in the Si 10\% treatment compared to the Si $0 \%$ treatment).

The $\mathrm{C} / \mathrm{N}$ ratio in the water phase decreased between the initial phase and the end of the incubation due to decreasing $\mathrm{C}$ concentrations, but there were no differences between the treatments concerning this decrease in the water phase. The $\mathrm{C} / \mathrm{N}$ ratio of the Eriophorum shoots generally decreased as well during the decomposition period. In the "low-P" treatment group, the decrease was more pronounced for the Si addition treatments, compared to the treatment without $\mathrm{Si}$ addition. The $\mathrm{C} / \mathrm{N}$ ratio decreased due to higher absolute losses in the $\mathrm{C}$ mass fraction compared to losses in the $\mathrm{N}$ mass fraction. The $\mathrm{N}$ mass fraction was higher in those treatments that did not receive Si fertilization. Matzner and Berg [35] found high $\mathrm{N}$ contents in litter to act as trigger for decomposition, whereas it inhibits decomposition in later stages of decomposition. The comparatively high $\mathrm{CO}_{2}$ production rate in the Si $0 \%$ treatments can also be interpreted as triggered by high $\mathrm{N}$ mass fractions of the litter. The "low-P Si 10\%" treatment showed an increase in the C mass fraction after the incubation. The mass fraction in \% always refers to the total material measured. The increase in C mass fraction, here, is explained by a strong leaching of $\mathrm{Si}$ from the plant material of this treatment. The share of $C$ in this material, thus, increased during the incubation. In all other treatments the Si leaching was smaller and the release of $C$ into the solution was higher.

We further hypothesized (III) the onset of methanogenesis to be earlier for the decomposition of Si-rich litter, than for Si-poor litter. We expected this due to several processes. First the available electron acceptors should be depleted more rapidly due to the higher $\mathrm{CO}_{2}$ production, which we expected (hypothesis II) [14]. Second, we expected a generally higher $\mathrm{CH}_{4}$ production due to a direct stimulating effect of $\mathrm{Si}$. We confirmed this hypothesis (III) for the Eriophorum shoot incubation: The onset of methanogenesis for the Si $10 \%$ treatment was earlier than that of the Si $0 \%$ treatment, such that more $\mathrm{CH}_{4}$ was produced during the experiment in these incubations. Until methanogenesis began, unexpectedly less $\mathrm{CO}_{2}$ was produced in the Si-addition treatments than in the treatments without Si. The electron acceptors in the Si-addition treatments had thus been used up more rapidly and apparently incompletely, since methanogenesis started earlier despite lower $\mathrm{CO}_{2}$ production before onset of methanogenesis. Although this suggests another direct effect of Si addition on methanogenesis or pathways of anaerobic C mineralization, we cannot clarify this aspect from available data of this experiment.

This partly met our expectation of the hypothesis (I). However, the reasons for the different behavior of $\mathrm{CO}_{2}$ and $\mathrm{CH}_{4}$ production rates remain unclear. As discussed before, the high-Si treatment did not show a higher $\mathrm{CO}_{2}$ production rate. During long-term incubation, there was no difference in $\mathrm{CO}_{2}$ production rates, and during the initial phase, the Si $0 \%$ treatment showed the highest production rate.

Wainwright et al. [13] found Si to have a positive effect on the growth of fungi in both oligotrophic and nutrient rich media, and Voronin and Mukhin [36] found saprotrophic fungi to be an initial key factor to feed anaerobic degradation pathways ending up in methanogenesis. We can only speculate about the abundance of fungi and methanogens in our experiments, but higher abundances of fungi, which initiate the decomposition of lignin and cellulose for further fermentation and oxidation and the concomitant high abundance of methanogens, as described by Voronin and Mukhin [36], could be a reason for the high $\mathrm{CH}_{4}$ production rates we observed when Si availability was high. 
In relation to the litter quality assessed by FTIR, the share of phenolic compounds increased strongly during the incubation for the Si $1 \%$ and the Si $10 \%$ treatment of the low-P treatment group, and it increased for the Si $0 \%$ and the Si $10 \%$ treatment of the high-P treatment group. The increase in the share of phenolic OH in the "low-P Si 10\%" was highest compared to the "low-P Si 1\%" and the "low-P Si 0\%" treatment. For the high-P treatment group the magnitude of the increase did not differ with the Si treatment. The strong increase in the share of phenolic $\mathrm{OH}$ in the remaining litter of the "low-P Si $10 \%$ " treatment coincided with a high $\mathrm{CH}_{4}$ production rate, but also with a comparatively low $\mathrm{CO}_{2}$ production rate.

It is likely that microbial communities developed differently in the treatments due to the experimental amendments. This was, however, beyond the scope of our study. Nevertheless, we pretreated all incubations in the same way by inoculating them with the same peat solution. Therefore, the different incubations are as comparable as possible.

When graminoid litter with different Si mass fractions undergoes decomposition in anaerobic environments like fen ecosystems, differences in the Si mass fraction and the simultaneous changes obviously influence the decomposition and the decomposition pathways of the litter, as shown in our study. Nevertheless, the $\mathrm{CO}_{2}$ production rate in the decomposition of Eriophorum shoots was not influenced by the Si mass fraction of the litter, even though Si changed the stoichiometric composition of the biomass. Albeit not significantly, the $\mathrm{CH}_{4}$ production rate was apparently higher for litter with a higher Si mass fraction.

Therefore, different input rates of plant available $\mathrm{Si}-$ whether from bedrock weathering or from external sources (ash, precipitation, runoff from the catchment) - may influence the decomposition processes of the vegetation grown under such different $\mathrm{Si}$ availabilities, and thus, affect greenhouse gas production in peatlands by stimulating higher and more rapid $\mathrm{CH}_{4}$ production under high $\mathrm{Si}$ availability.

The roots, the main peat-forming parts of the graminoid vegetation, are not expected to be influenced by different $S i$ availabilities directly, since different $S i$ availabilities in the soil do not necessarily lead to significantly higher Si mass fractions in the roots. The lack of root aphids in the $\mathrm{Si} 10 \%$ treatment of the first part of the study, however, suggests that $\mathrm{Si}$ may have an indirect influence on root growth, by inhibiting pest infestation. Overall, $\mathrm{Si}$ was accumulated rather in the shoots than in the roots. The shoots that grew under high $\mathrm{Si}$ availability, however, accumulated $\mathrm{Si}$ according to its availability. When this shoot material decomposes, it decomposes faster than the roots and is the main contributor to $\mathrm{CO}_{2}$ and $\mathrm{CH}_{4}$ emissions from a fen peatland [21]. The Si effect on $\mathrm{CO}_{2}$ production rates was fast, leading to higher $\mathrm{CO}_{2}$ production from the shoots that grew under low $\mathrm{Si}$ availability when the plants got in contact with water, e.g., in water filled depressions or hollows. $\mathrm{The}^{\mathrm{CH}_{4}}$ effect was delayed and displayed, in contrast, higher $\mathrm{CH}_{4}$ production from the shoots grown under high Si availability.

The root biomass may be less prone to diseases or pests and the overall productivity may increase if the Si input into an ecosystem increases, but this remains to be tested. The changes in stoichiometry and carbon compounds only have a small influence on $\mathrm{CO}_{2}$ production, but $\mathrm{CH}_{4}$ production from decaying shoot biomass may increase with increasing Si availability.

\section{Methods}

\subsection{Part I-Biomass Characterization}

\subsubsection{Extraction and Preparation of Plants}

The investigated plant species Eriophorum vaginatum, L. was chosen for this experiment due to its broad abundance in minerotrophic peatlands [5]. The planting experiment was also conducted with Carex rostrata Stokes, but it showed only poor growth within the experimental period, and hence, the results are presented in the supporting material only.

Individual plants were sampled in autumn 2018 from the minerotrophic peatland "Schlöppnerbrunnen" in the German Fichtelgebirge mountain range (geographic coordi- 
nates: $50^{\circ} 7^{\prime} 56.83^{\prime \prime} \mathrm{N} ; 11^{\circ} 52^{\prime} 53.94^{\prime \prime} \mathrm{E}$ ) at $706 \mathrm{~m}$ a.s.l. This research site was formerly used by many other authors [37-39]. The sampling was done using a spade and a saw to get intact peat sods and preserve a root length of at least $20-30 \mathrm{~cm}$. The material was transported in plastic boxes to the University of Bayreuth and stored in a cold greenhouse. After excavation, individual plants were separated and washed to remove adherent peat. The root length and the length of aboveground biomass was adjusted for the 30 individuals to $10 \mathrm{~cm}$ long roots and $5 \mathrm{~cm}$ long shoots. The individuals were stored with their roots immersed in water over night.

\subsubsection{Substrate Preparation}

The substrate for the planting experiment was based on unamended horticultural fibric peat from a peatland in Lower Saxony, Germany. This peat was, depending on the treatment, mixed with different portions of $\mathrm{SiO}_{2}$ (added as fumed silica, Aerosil-300, Evonik, Germany). The mixing was done in a concrete mixer for approximately $20 \mathrm{~min}$. The control treatment contained no added $\mathrm{SiO}_{2}$ and had a background mass fraction of $0.16 \%$ $( \pm 0.03) \mathrm{Si}$ as measured by $\mathrm{X}$-ray fluorescence $(\mathrm{XRF})$ (procedure described in chapter 4.3$)$. It was likewise pre-treated in the concrete mixer to minimize differences, due to handling. The $\mathrm{Si} 1 \%$ treatment contained $1 \%$ weight $\mathrm{SiO}_{2}$ and the $\mathrm{Si} 10 \%$ treatment contained $10 \%$ $\mathrm{SiO}_{2}$, resulting in three types of substrates. $500 \mathrm{~g}$ of substrate was filled in 20 pots each. The substrate was moistened with $1 \mathrm{~L}$ of deionized water per pot.

\subsubsection{Planting and Fertilization}

Two days after sampling in the field, the plants were planted in the prepared pots. Each species was planted in each substrate type in 10 replicates.

To favor plant growth, the plants were fertilized three times (altogether $100 \mathrm{~mL}$ ) during the growing season. The fertilizer was prepared with two different amounts of $\mathrm{PO}_{4}$ to establish two different $\mathrm{P}$ treatments (Table 2). The first fertilization was applied directly after planting (resulting in $2.9 \mathrm{mg} \mathrm{P}$, and $17.3 \mathrm{mg}$ P per pot respectively). Five pots of each plant and substrate type received the low-P fertilizer, whereas the others received the high-P fertilizer. The second fertilization was applied after one month, the third after three months with a smaller amount of fertilizer on both occasions (resulting in $2.2 \mathrm{mg} \mathrm{P}$ and 13,0 mg P per pot respectively) (see also Table A1 in Appendix A). This resulted in six different treatments per species, three levels of $\mathrm{Si}$ in the substrate and two levels of $\mathrm{P}$ in the fertilization in a full factorial design.

Table 2. Composition of the fertilizer solution added per pot over the complete growing season. Two different fertilizers were prepared, one containing a small concentration of $\mathrm{K}_{2} \mathrm{HPO}_{4}$, the other one containing a high concentration of $\mathrm{K}_{2} \mathrm{HPO}_{4}$.

\begin{tabular}{|c|c|c|c|c|c|c|c|c|c|c|c|c|c|c|c|}
\hline Nutrient & $\mathbf{K}$ & $\mathbf{P}$ & $\mathbf{N}$ & $\mathrm{Ca}$ & $\mathrm{Cl}$ & $\mathrm{Mg}$ & B & Mo & $\mathrm{Na}$ & $\mathrm{Zn}$ & $\mathrm{Cu}$ & Co & Mn & $\mathrm{Fe}$ & $S$ \\
\hline $\begin{array}{c}\mathrm{mg} / 100 \mathrm{~mL} \\
(\hat{=} \mathrm{mg} \text { per pot })\end{array}$ & $\begin{array}{l}18.1 \text { or } \\
109.5\end{array}$ & $\begin{array}{c}7.1 \text { or } \\
43.4\end{array}$ & 28.0 & 3.4 & 3.6 & 4.9 & 0.26 & 0.9 & 6.4 & 1.43 & 0.13 & 0.04 & 0.98 & 0.5 & 7.6 \\
\hline
\end{tabular}

The experiment was conducted in a greenhouse at a temperature of $20{ }^{\circ} \mathrm{C}$ and with greenhouse lights ( $400 \mathrm{~W}, 35,000 \mathrm{~lm}$, Powerstar HQI-TS 400W D Pro, Osram, Munich, Germany) and a diurnal light cycle based on natural conditions of late spring in the midlatitudes ( $14 \mathrm{~h}$ light, $10 \mathrm{~h}$ dark). The pots were watered every second day with distilled water to avoid application of further nutrients. The pore water was regularly checked for changes in $\mathrm{pH}$.

\subsubsection{Harvest, Milling}

With the start of senescence, watering was stopped two weeks before harvesting the plants to facilitate senescence. The aboveground biomass was clipped and stored in paper bags. Thereafter, the substrate was removed manually from the roots first by shaking off most parts of the dry soil and then cleaning the roots from the adhered peat under 
constantly flowing water; the roots were also then stored in paper bags. One additional paper bag was taken per treatment to collect a pooled sample of material of plant species of each treatment and litter type. This material was later used for the incubation experiment (see below). After harvesting the above- and belowground material, the biomass in all paper bags was dried in a drying cabinet at about $20^{\circ} \mathrm{C}$ for one week. The low temperature was chosen to maintain environmental conditions.

Each individual plant sample ( 120 in total) was ground using an ultra-centrifugal mill (Retsch, ZM1, Haan, Germany) at 10,000 rpm. This material was used for P and Si extractions and for $\mathrm{C}$ and $\mathrm{N}$ elemental analysis.

\subsubsection{Analysis of the Biomass}

All samples were analyzed on their $\mathrm{Si}, \mathrm{P}, \mathrm{N}$ and $\mathrm{C}$ mass fraction. The mass fraction of amorphous $\mathrm{Si}$ was determined by alkaline extraction following the procedure of Meunier et al. [40]. $30 \mathrm{mg}$ of the milled material was funneled into $50 \mathrm{~mL}$ flat bottom tubes. Then, $30 \mathrm{~mL}$ of $0.1 \mathrm{M} \mathrm{Na}_{2} \mathrm{CO}_{3}$ (Roth) solution was added, the tubes were shaken, closed with lids, and then boiled for $5 \mathrm{~h}$ at $85^{\circ} \mathrm{C}$ in a heating block (DigiPrep Jr, SCP Science, Montreal, Canada). The tubes were shaken again once each hour. After the boiling period, we waited for the solid parts to settle before filtering the supernatant through $0.2 \mu \mathrm{m}$ PET syringe filters (Macherey-Nagel, Düren, Germany). The filtered supernatant was retained in polypropylene tubes. The concentration of total Si was then analyzed with an ICP OES (Varian, Vista-pro radial, Palo Alto, USA) in the central analytical laboratory of BayCEER, Bayreuth, Germany. The total P content was determined following EN 13805, 2002 [41]. Prior to sample digestion, microwave vessels were cleaned by a blank digestion. Afterwards, $150-250 \mathrm{mg}$ of the ground plant material was added to the microwave tubes. A total of $3 \mathrm{~mL}$ of $65 \% \mathrm{HNO}_{3}$ (Roth) and $2 \mathrm{~mL}$ of $30 \% \mathrm{H}_{2} \mathrm{O}_{2}$ were added, and the tubes were closed with lids and shaken. After $14 \mathrm{~h}$ of resting, the tubes were heated in a microwave to $180{ }^{\circ} \mathrm{C}$ for $20 \mathrm{~min}$ and subsequently kept boiling for $15 \mathrm{~min}$. After cooling down, the tubes were opened and quantitatively transferred into new vials with ultra-pure water. Therefore, a diluted sample of $50 \mathrm{~mL}$ was gained. The P mass fraction of these samples was determined again by ICP OES (Varian, Vista-pro radial, Palo Alto, USA) as above. The $\mathrm{C}$ and $\mathrm{N}$ mass fractions of the milled material were determined with a $\mathrm{CN}$ elemental analyzer (EA 3000, Eurovector/Hekatech, Milano, Italy/Wegberg, Germany). Therefore, approximately $3 \mathrm{mg}$ of the dried and milled plant material was balanced and funneled in a tin capsule and subsequently analyzed at the Institute of Landscape Ecology at the University of Münster, Germany.

\subsubsection{FTIR Analysis}

The pooled plant biomass samples were stored in the dark and transported to the University of Münster. Here, the material was cut into approximately $1 \mathrm{~cm}$ long pieces by hand, thoroughly mixed and again stored dry and in the dark until further use.

A subsample of the pooled plant material was finely ground using a mixer mill (Retsch MM 400). Then, $2 \mathrm{mg}$ of the finely ground sample were mixed with $200 \mathrm{mg}$ of potassium bromide (KBr, IR grade, Sigma Aldrich, St. Louis, UAS) in a mortar, obtaining a homogenous powder. The powder was placed in a pelleting press and pressed into $13 \mathrm{~mm}$ pellets at a load of $8 \mathrm{t}$. The pellets were immediately transferred into the FTIR spectrometer (Cary 600, Agilent, Santa Clara, CA, USA), and 32 scans of the sample were recorded and averaged to obtain the final infrared absorption spectrum. The spectra were preprocessed in R [42] using the function ir_bc() from the R package "ir" [43] (version 0.0.0.9000) which is based on a "rubberband" algorithm from the spc.hyperspec() function of the R package hyperSpec [44]. To interpret the FTIR spectra, we assigned absorption features to major structural moieties in organic matter as explained in Table 1. 


\subsection{Part II-Plant Decomposition Experiment}

\subsubsection{Preparation of the Incubation}

The incubation experiment with Eriophorum shoots was performed in $120 \mathrm{~mL}$ injection bottles (Glasgerätebau Ochs, Lenglern, Germany). For the incubation, $500 \mathrm{mg}$ of dry plant material was funneled into the bottles. Then $200 \mathrm{mg}$ of dry peat was added. The peat used here was a long-term oxidized sod peat from a bog in Lower Saxony, Germany (see Agethen and Knorr [7] for characterization of this peat material). It was crumbled by hand and then sieved through a $2 \mathrm{~mm}$ sieve to obtain homogenous material. Subsequently, $30 \mathrm{~mL}$ of ultrapure water was added. To inoculate the incubations with an active microbial community of a fen, $100 \mu \mathrm{L}$ of fen peat filtrate (approximately $30 \mu \mathrm{m}$ pore size) from the Schlöppnerbrunnen fen was added.

The bottles were closed with butyl rubber stoppers and then flushed with nitrogen for about $20 \mathrm{~min}$. Thereby, oxygen $\left(\mathrm{O}_{2}\right)$ and $\mathrm{CO}_{2}$ in the bottles were removed and the bottles prepared for the following incubations. This resulted in six treatments with Eriophorum shoots (see variants of biomass above) and a control treatment without plant material (Table A2).

\subsubsection{Incubation Procedure}

During the entire experiment, the bottles were stored in an incubator at $15^{\circ} \mathrm{C}$ in the dark, and they were only shortly removed for samplings. In regular intervals, measurements of the $\mathrm{CO}_{2}$ and $\mathrm{CH}_{4}$ concentration in the headspace of the incubation bottles were taken using a gas chromatograph (SRI Instruments, Earl St. Torrance, USA) equipped with an FID detector and methanizer. An amount of $2 \mathrm{~mL}$ of $\mathrm{N}_{2}$ was injected into the headspace, mixed with the headspace gas, and then $2 \mathrm{~mL}$ of diluted gas were taken from the bottles. This was done to avoid a change of pressure in the headspace over longer time periods. The fist GC measurement in the shoot incubation was performed $24 \mathrm{~h}$ after the $\mathrm{N}_{2}$ flushing. It was followed by three more measurements within 10 days; this period is hereafter referred to as "initial phase". Thereafter, the bottles were opened, $4 \mathrm{~mL}$ of water was taken with a syringe and a cannula and immediately filtered through $0.22 \mu \mathrm{m}$ nylon syringe filters (MACHEREY-NAGEL, Düren, Germany) into centrifuge tubes. Then, $10 \mathrm{~mL}$ of ultrapure water was added to the incubation bottles to ensure to have enough water for a second sampling. This was followed by $20 \mathrm{~s}$ of intense $\mathrm{N}_{2}$ flushing, closure again with butyl rubber stoppers, and $20 \mathrm{~min} \mathrm{~N}_{2}$ flushing of the headspace. Twenty-four hours after flushing, the next concentration measurement was taken at the GC. From then on, these measurements were conducted for 13 weeks with measurements once a week, in order to capture further ongoing decomposition after initial leaching and decomposition effects had passed. This was the "long-term phase" of the incubation.

The water samples from the incubations were prepared for different analyses: The concentrations of dissolved organic carbon (DOC) and dissolved nitrogen (TN) were measured using a V-CPN Analyzer, (Shimadzu, Tokyo, Japan). To determine major anions, ion chromatography (883 Basic IC plus Metrohm, Herisau, Switzerland) was employed, and for the total concentration of other major elements such as $\mathrm{Si}$ and total $\mathrm{P}$, we used inductively coupled plasma optical emission spectroscopy (ICP-OES; SpectroBlue, Kleve, Germany).

\subsubsection{Analysis after Decomposition}

After the 14 weeks of incubation, water sampling was done directly after opening the bottles. The samples were treated and analyzed in the same way as described above. Then, the still discernible plant fragments were collected from the bottles, freeze dried (Christ Alpha 1-4 LDplus, Osterode am Harz, Germany) and milled with the same equipment as used on the initial material. Afterwards, the material was characterized again using FTIR spectroscopy (see above). 


\subsubsection{Statistical Analysis}

Calculations on statistically significant differences were done using R (R-Core-Team, 2018). We assumed a Gaussian distribution within the treatment groups. After a test on homoscedasticity (var test) a $t$-test ( $t$ test) or a welch-test ( $t$ test) was performed, respectively, depending on the results of the prior test. The significance level was set to $\alpha=0.05$. Diagrams were created using R [42] and the R package Hmisc [45]. Unless otherwise noted, the standard deviation of the mean is given in bar plots.

\subsection{Wild Plant Characterization for Comparison}

In summer 2018, 24 shoot samples were collected from plants of three species from the Schlöppnerbrunnen fen, the same site at which the plants for the growing experiment were taken. These species were Carex rostrata, Eriophorum vaginatum and Molinia caerulea Moench. The shoots were frozen and subsequently freeze dried (Christ Alpha 1-4 LDplus, Osterode am Harz, Germany).

The plants were milled according to the procedure described in Section 4.1.4. Milled samples were subjected to an FTIR analysis (as described in Section 4.1.6) and total element mass fractions were determined with X-ray fluorescence spectroscopy at the University of Münster, Germany. For the latter, a wavelength dispersive X-ray fluorescence spectrometer (WD-XRF Rigaku ZSX Primus II, Tokyo, Japan) was used. Therefore, $500 \mathrm{mg}$ of the sample was formed into a pellet at a load of 6-7 $\mathrm{t}$ using a pellet die (Specac, Orpington, UK), and pellets were stored in polyethylene bags in a desiccator until measurement.

\section{Conclusions}

Do higher Si mass fractions go along with decreased mass fraction of nutrients and changes in shares of carbon compounds (decrease of hardly degradable compounds)? This was found for the $\mathrm{N}$ mass fraction of Eriophorum, especially for the shoots. The FTIR ratios displayed a decreasing share of lignin, aromatic $\mathrm{C}=\mathrm{C}$ and $\mathrm{COO}^{-}$carbonylic and carboxylic, aliphatic structures (waxes and lipids) and phenolic $\mathrm{OH}$ with increasing an $\mathrm{Si}$ mass fraction. The roots accumulated much less than Si. Since the roots are the main peat forming tissues, they are obviously less influenced by different $\mathrm{Si}$ availabilities than the shoots.

Does the Si mass fraction and the concomitant changes (nutrient mass fraction, share of carbon compounds) influence the decomposition of plant litter from fens? For Eriophorum shoots, the $\mathrm{CH}_{4}$ production rate was apparently higher, albeit not significantly, for litter with a higher $\mathrm{Si}$ mass fraction. The $\mathrm{CO}_{2}$ production rate was only during the initial phase influenced by the $\mathrm{Si}$ mass fraction. It displayed a lower $\mathrm{CO}_{2}$ production rate for higher $\mathrm{Si}$ mass fractions. Afterwards, the $\mathrm{CO}_{2}$ production was equal between the treatments. The influence of high Si mass fractions on decomposition processes, thus, differs between the respective pathway and probably also with species and with tissue.

Is litter grown under high $\mathrm{Si}$ uptake less recalcitrant than litter grown under low $\mathrm{Si}$ mass fractions? The share of recalcitrant compounds seems to be higher in those plants that have a low $\mathrm{Si}$ mass fraction. This does not seem to influence $\mathrm{CO}_{2}$ production rates in the long-term. Meanwhile, the $\mathrm{CH}_{4}$ production tends to be faster and set earlier in incubations with litter having an increasing Si mass fraction, and with an altered share of different carbon compounds.

Author Contributions: A.H. conducted the experiments and wrote the manuscript with major contributions by K.-H.K. and J.S. The funding was acquired by J.S. and K.-H.K. All authors have read and agreed to the published version of the manuscript.

Funding: The work was funded by the German Research Foundation (DFG), grant number SCHA 1822/7-1 to Jörg Schaller and grant number KN 929/11-1 to Klaus-Holger Knorr. We acknowledge support from the Open Access Publication Fund of the University of Münster.

Institutional Review Board Statement: Not applicable.

Informed Consent Statement: Not applicable. 
Data Availability Statement: Data is contained within the article.

Acknowledgments: We thank Martina Kulzer (University of Bayreuth), who conducted her bachelor thesis taking care of the plant breeding and the plant's characterization with major help of Fabian Nützel (Plant ecology, University of Bayreuth). Tanja Broder and Viktoria Ratachin (University of Münster) performed the ICP OES Measurement and Tanja Broder evaluated and preprocessed the ICP OES data. Rabea Klümpers, Lisa Närtker und Michael Fleischer (University of Münster) helped with analyses of the incubation experiment. Madeleine Supper and Ulrike Berning-Mader (University of Münster) performed DOC/TN and IC measurements as well as C/N measurements of the plant material. Henning Teickner (University of Münster) helped with data handling and evaluation of FITR Data. We are also immensely grateful to Celeste Brennecka (University of Münster) for her language editing on an earlier version of the manuscript. Two anonymous reviewers helped to improve a former version of this manuscript.

Conflicts of Interest: The authors declare no conflict of interest. The funders had no role in the design of the study; in the collection, analyses, or interpretation of data; in the writing of the manuscript, or in the decision to publish the results.

\section{Appendix A}

Table A1. Composition of fertilizer solutions 1-5 in the applied concentration.

\begin{tabular}{|c|c|c|c|}
\hline $\begin{array}{l}\text { Fertilizer } \\
\text { Number }\end{array}$ & Nutrient & $\begin{array}{c}\text { mmol } \mathrm{L}^{-1} \text { in Low-P } \\
\text { Fertilizer }\end{array}$ & $\begin{array}{c}\text { mmol } \mathrm{L}^{-1} \text { in High-P } \\
\text { Fertilizer }\end{array}$ \\
\hline \multirow[t]{2}{*}{1} & $\mathrm{~K}_{2} \mathrm{HPO}_{4}$ & 400.6 & 2438.4 \\
\hline & $\mathrm{NH}_{4} \mathrm{NO}_{3}$ & 800.4 & 800.4 \\
\hline 2 & $\mathrm{CaCl} \cdot 2 \mathrm{H}_{2} \mathrm{O}$ & 62.7 & 62.7 \\
\hline 3 & $\mathrm{MgSO}_{4}$ & 500.3 & 500.3 \\
\hline \multirow[t]{2}{*}{4} & $\mathrm{H}_{3} \mathrm{BO}_{3}$ & 14.8 & 14.8 \\
\hline & $\mathrm{NaMoO}_{4} \cdot 2 \mathrm{H}_{2} \mathrm{O}$ & 24.2 & 24.2 \\
\hline \multirow[t]{6}{*}{5} & $\mathrm{ZnSO}_{4} \cdot 7 \mathrm{H}_{2} \mathrm{O}$ & 63.3 & 63.3 \\
\hline & $\mathrm{CuSO}_{4} \cdot 5 \mathrm{H}_{2} \mathrm{O}$ & 5.0 & 5.0 \\
\hline & $\mathrm{CoSO}_{4} \cdot 7 \mathrm{H}_{2} \mathrm{O}$ & 2.0 & 2.0 \\
\hline & $\mathrm{MnCl} \cdot 4 \mathrm{H}_{2} \mathrm{O}$ & 29.2 & 29.2 \\
\hline & $\mathrm{FeSO}_{4} \cdot 7 \mathrm{H}_{2} \mathrm{O}$ & 25.0 & 25.0 \\
\hline & $\mathrm{Na}_{2} \mathrm{EDTA} \cdot 2 \mathrm{H}_{2} \mathrm{O}$ & 498.8 & 498.8 \\
\hline
\end{tabular}

Table A2. Treatment additions in the decomposition experiments.

\begin{tabular}{ccc}
\hline Treatment & Shoots & $\begin{array}{c}\text { Peat for Eriophorum- } \\
\text { Shoot Incubation }\end{array}$ \\
\hline Low-P; Si 0\% & $500 \mathrm{mg}$ & $200 \mathrm{mg}$ \\
Low-P; Si 1\% & $500 \mathrm{mg}$ & $200 \mathrm{mg}$ \\
Low-P; Si 10\% & $500 \mathrm{mg}$ & $200 \mathrm{mg}$ \\
High-P; Si 0\% & $500 \mathrm{mg}$ & $200 \mathrm{mg}$ \\
High-P; Si 1\% & $500 \mathrm{mg}$ & $200 \mathrm{mg}$ \\
High-P; Si 10\% & $500 \mathrm{mg}$ & $200 \mathrm{mg}$ \\
Peat control & $/$ & $200 \mathrm{mg}$
\end{tabular}

The peat + biomass treatments and the peat control were 5 times replicated. All treatments received $30 \mathrm{ml}$ of ultrapure water and an inoculum of $100 \mu \mathrm{L}$ fen DOM filtrate. 
Table A3. Selected FTIR ratios of plants before and after incubation.

\begin{tabular}{|c|c|c|c|c|c|c|}
\hline & $1350 / 1090$ & $1630 / 1090$ & $1720 / 1090$ & $2850 / 1090$ & 2920/1090 & $3380 / 1090$ \\
\hline \multicolumn{7}{|c|}{ Eriophorum shoots before incubation } \\
\hline Si $0 \%$ & 0.493 & 0.572 & 0.372 & 0.466 & 0.663 & 1.263 \\
\hline Si $1 \%$ low $\mathrm{P}$ & 0.441 & 0.509 & 0.343 & 0.395 & 0.570 & 1.122 \\
\hline Si $10 \%$ low P & 0.373 & 0.415 & 0.284 & 0.302 & 0.441 & 0.889 \\
\hline Si $1 \%$ high $\mathrm{P}$ & 0.428 & 0.442 & 0.321 & 0.374 & 0.539 & 1.076 \\
\hline Si $10 \%$ high $\mathrm{P}$ & 0.362 & 0.396 & 0.274 & 0.288 & 0.425 & 0.866 \\
\hline \multicolumn{7}{|c|}{ Eriophorum shoots after incubation } \\
\hline Si $0 \%$ low $\mathrm{P}$ & 0.511 & 0.593 & 0.487 & 0.484 & 0.675 & 1.092 \\
\hline Si $1 \%$ low P & 0.448 & 0.521 & 0.277 & 0.394 & 0.556 & 1.319 \\
\hline Si $10 \%$ low P & 0.463 & 0.522 & 0.278 & 0.411 & 0.573 & 1.332 \\
\hline Si 0\% high $\mathrm{P}$ & 0.428 & 0.453 & 0.248 & 0.380 & 0.539 & 1.303 \\
\hline Si 1\% high $\mathrm{P}$ & 0.465 & 0.511 & 0.427 & 0.419 & 0.585 & 0.968 \\
\hline Si $10 \%$ high $\mathrm{P}$ & 0.393 & 0.449 & 0.352 & 0.346 & 0.498 & 0.931 \\
\hline \multicolumn{7}{|c|}{ Eriophorum roots before incubation } \\
\hline Si $0 \%$ low $\mathrm{P}$ & 0.525 & 0.633 & 0.504 & 0.501 & 0.688 & 1.207 \\
\hline Si $1 \%$ low $\mathrm{P}$ & 0.482 & 0.520 & 0.438 & 0.441 & 0.617 & 1.096 \\
\hline Si $10 \%$ low P & 0.396 & 0.422 & 0.343 & 0.340 & 0.485 & 0.882 \\
\hline Si 0\% high $\mathrm{P}$ & 0.433 & 0.525 & 0.275 & 0.367 & 0.524 & 1.279 \\
\hline Si 1\% high $\mathrm{P}$ & 0.446 & 0.511 & 0.283 & 0.377 & 0.533 & 1.265 \\
\hline Si $10 \%$ high $\mathrm{P}$ & 0.406 & 0.450 & 0.230 & 0.347 & 0.506 & 1.297 \\
\hline \multicolumn{7}{|c|}{ Carex roots before incubation } \\
\hline Si $0 \%$ low $\mathrm{P}$ & 0.5075 & 0.68918 & 0.3124 & 0.4237 & 0.6045 & 1.4629 \\
\hline Si $1 \%$ low $\mathrm{P}$ & 0.4519 & 0.5942 & 0.24698 & 0.3380 & 0.5157 & 1.3947 \\
\hline Si $10 \%$ low P & 0.4340 & 0.6517 & 0.2708 & 0.3919 & 0.5796 & 1.4432 \\
\hline Si 0\% high $\mathrm{P}$ & 0.4810 & 0.6138 & 0.3014 & 0.3995 & 0.5706 & 1.3940 \\
\hline Si $1 \%$ high $\mathrm{P}$ & 0.4490 & 0.6030 & 0.2749 & 0.3675 & 0.5486 & 1.3296 \\
\hline Si $10 \%$ high $\mathrm{P}$ & 0.4186 & 0.6001 & 0.2521 & 0.3683 & 0.5518 & 1.3658 \\
\hline
\end{tabular}

Table A4. Tables of $p$-values belonging to Figure 6 .

\begin{tabular}{|c|c|c|c|c|c|c|c|c|c|c|c|c|c|c|c|}
\hline Si & Time & $\begin{array}{c}\text { Low } \\
\text { P Si } \\
0 \%\end{array}$ & $\begin{array}{c}\text { Low } \\
\text { P Si } \\
0 \%\end{array}$ & $\begin{array}{c}\text { Low } \\
\text { P Si } \\
1 \%\end{array}$ & $\begin{array}{c}\text { Low } \\
\text { P Si } \\
1 \%\end{array}$ & $\begin{array}{l}\text { Low } \\
\text { P Si } \\
10 \%\end{array}$ & $\begin{array}{l}\text { Low } \\
\text { P Si } \\
10 \%\end{array}$ & $\begin{array}{c}\text { High } \\
\text { P Si } \\
0 \%\end{array}$ & $\begin{array}{c}\text { High } \\
\text { P Si } \\
0 \%\end{array}$ & $\begin{array}{c}\text { High } \\
\text { P Si } \\
1 \%\end{array}$ & $\begin{array}{c}\text { High } \\
\text { P Si } \\
\text { 1\% }\end{array}$ & $\begin{array}{c}\text { High } \\
\text { Si } \\
10 \%\end{array}$ & $\begin{array}{c}\text { High } \\
\text { Si } \\
10 \%\end{array}$ & $\begin{array}{l}\text { Peat } \\
\text { Con- } \\
\text { trol }\end{array}$ & $\begin{array}{l}\text { Peat } \\
\text { Con- } \\
\text { trol }\end{array}$ \\
\hline Time & I & Beg. & End & Beg. & End & Beg. & End & Beg. & End & Beg. & End & Beg. & End & Beg. & End \\
\hline Low & & & 5.364 & & 2.361 & & & & 4.549 & & 1.661 & & 8.786 & & 4.029 \\
\hline $\begin{array}{c}\text { P Si } \\
0 \%\end{array}$ & Beg. & / & $\stackrel{\times}{10^{-9}}$ & $\underline{0.0079}$ & $\begin{array}{c}\times \\
10^{-6}\end{array}$ & $\underline{0.0079}$ & 0.0098 & $\underline{0.5476}$ & $\stackrel{\times}{10^{-8}}$ & $\underline{0.0079}$ & $\begin{array}{c}\times \\
10^{-6}\end{array}$ & $\underline{0.0079}$ & $\begin{array}{c}\times \\
10^{-6}\end{array}$ & $\underline{0.0079}$ & $\stackrel{\times}{10^{-7}}$ \\
\hline $\begin{array}{c}\text { Low } \\
\text { P Si } \\
0 \%\end{array}$ & End & & / & / & $\underline{0.0079}$ & / & $\underline{0.0357}$ & / & $\underline{0.0714}$ & / & $\underline{0.0079}$ & / & $\underline{0.0079}$ & / & $\underline{0.0079}$ \\
\hline $\begin{array}{c}\text { Low } \\
\text { P Si } \\
1 \%\end{array}$ & Beg. & & & / & $\begin{array}{c}3.704 \\
\times \\
10^{-6}\end{array}$ & $\underline{0.0079}$ & 0.0114 & $\underline{0.0079}$ & $\begin{array}{c}4.765 \\
\times \\
10^{-7}\end{array}$ & $\underline{0.0925}$ & $\begin{array}{c}2.596 \\
\times \\
10^{-6}\end{array}$ & $\underline{0.0079}$ & $\begin{array}{c}1.166 \\
\times \\
10^{-5}\end{array}$ & $\underline{0.0079}$ & 0.2764 \\
\hline $\begin{array}{l}\text { Low } \\
\text { P Si } \\
1 \%\end{array}$ & End & & & & / & / & $\underline{0.0357}$ & / & $\underline{0.0357}$ & / & $\underline{0.6905}$ & / & $\underline{0.0079}$ & / & 0.0079 \\
\hline $\begin{array}{l}\text { Low } \\
\text { P Si } \\
10 \%\end{array}$ & Beg. & & & & & / & 0.0138 & $\underline{0.0079}$ & 0.0056 & $\underline{0.0079}$ & $\begin{array}{c}1.638 \\
\times \\
10^{-7}\end{array}$ & $\underline{0.8413}$ & $\begin{array}{c}3.995 \\
\times \\
10^{-8}\end{array}$ & $\underline{0.0079}$ & 0.0012 \\
\hline $\begin{array}{l}\text { Low } \\
\text { P Si } \\
10 \%\end{array}$ & End & & & & & & / & / & $\underline{0.0182}$ & / & 0.0357 & / & $\underline{1}$ & / & 0.0357 \\
\hline $\begin{array}{c}\text { High } \\
\text { P Si } \\
0 \%\end{array}$ & Beg. & & & & & & & / & $\begin{array}{c}7.093 \\
\times \\
10^{-7}\end{array}$ & $\underline{0.0079}$ & $\begin{array}{c}2.408 \\
\times \\
10^{-9}\end{array}$ & $\underline{0.0079}$ & $\begin{array}{c}4.064 \\
\times \\
10^{-6}\end{array}$ & $\underline{0.8413}$ & 0.0003 \\
\hline
\end{tabular}


Table A4. Cont.

\begin{tabular}{|c|c|c|c|c|c|c|c|c|c|c|c|c|c|c|c|}
\hline Si & Time & $\begin{array}{l}\text { Low } \\
\text { P Si } \\
0 \%\end{array}$ & $\begin{array}{l}\text { Low } \\
\text { P Si } \\
0 \%\end{array}$ & $\begin{array}{l}\text { Low } \\
\text { P Si } \\
1 \%\end{array}$ & $\begin{array}{c}\text { Low } \\
\text { P Si } \\
1 \%\end{array}$ & $\begin{array}{l}\text { Low } \\
\text { P Si } \\
10 \%\end{array}$ & $\begin{array}{l}\text { Low } \\
\text { P Si } \\
10 \%\end{array}$ & $\begin{array}{c}\text { High } \\
\text { P Si } \\
0 \%\end{array}$ & $\begin{array}{c}\text { High } \\
\text { P Si } \\
0 \%\end{array}$ & $\begin{array}{c}\text { High } \\
\text { P Si } \\
1 \%\end{array}$ & $\begin{array}{c}\text { High } \\
\text { P Si } \\
1 \%\end{array}$ & $\begin{array}{c}\text { High } \\
\text { Si } \\
10 \%\end{array}$ & $\begin{array}{c}\text { High } \\
\text { Si } \\
10 \%\end{array}$ & $\begin{array}{l}\text { Peat } \\
\text { Con- } \\
\text { trol }\end{array}$ & $\begin{array}{l}\text { Peat } \\
\text { Con- } \\
\text { trol }\end{array}$ \\
\hline Time & 1 & Beg. & End & Beg. & End & Beg. & End & Beg. & End & Beg. & End & Beg. & End & Beg. & End \\
\hline $\begin{array}{c}\text { High } \\
\text { P Si } \\
0 \%\end{array}$ & End & & & & & & & & / & / & $\underline{0.0357}$ & / & $\underline{0.0357}$ & / & $\underline{0.0357}$ \\
\hline $\begin{array}{c}\text { High } \\
\text { P Si } \\
1 \%\end{array}$ & Beg. & & & & & & & & & / & $\begin{array}{c}4.547 \\
\times \\
10^{-6}\end{array}$ & $\underline{0.0079}$ & $\begin{array}{c}1.294 \\
\times \\
10^{-5}\end{array}$ & $\underline{0.0079}$ & 0.0016 \\
\hline $\begin{array}{c}\text { High } \\
\text { P Si } \\
1 \%\end{array}$ & End & & & & & & & & & & / & / & $\underline{0.0079}$ & / & $\underline{0.0079}$ \\
\hline $\begin{array}{c}\text { High } \\
\text { P Si } \\
10 \% \\
\end{array}$ & Beg. & & & & & & & & & & & / & $\begin{array}{c}2.331 \\
\times \\
10^{-5} \\
\end{array}$ & $\underline{0.0079}$ & $\begin{array}{c}1.797 \\
\times \\
10^{-8} \\
\end{array}$ \\
\hline $\begin{array}{l}\text { High } \\
\text { P Si } \\
10 \%\end{array}$ & End & & & & & & & & & & & & / & / & $\underline{0.0079}$ \\
\hline $\begin{array}{l}\text { Peat } \\
\text { Con- } \\
\text { trol }\end{array}$ & Beg. & & & & & & & & & & & & & / & $\begin{array}{c}2.521 \\
\times \\
10^{-7}\end{array}$ \\
\hline $\begin{array}{l}\text { Peat } \\
\text { Con- } \\
\text { trol }\end{array}$ & End & & & & & & & & & & & & & & / \\
\hline $\mathbf{P}$ & Time & $\begin{array}{l}\text { Low } \\
\text { P Si } \\
0 \%\end{array}$ & $\begin{array}{l}\text { Low } \\
\text { P Si } \\
0 \%\end{array}$ & $\begin{array}{l}\text { Low } \\
\text { P Si } \\
1 \%\end{array}$ & $\begin{array}{l}\text { Low } \\
\text { P Si } \\
1 \%\end{array}$ & $\begin{array}{l}\text { Low } \\
\text { P Si } \\
10 \%\end{array}$ & $\begin{array}{l}\text { Low } \\
\text { P Si } \\
10 \%\end{array}$ & $\begin{array}{c}\text { High } \\
\text { P Si } \\
0 \%\end{array}$ & $\begin{array}{c}\text { High } \\
\text { P Si } \\
0 \%\end{array}$ & $\begin{array}{c}\text { High } \\
\text { P Si } \\
1 \%\end{array}$ & $\begin{array}{c}\text { High } \\
\text { P Si } \\
1 \%\end{array}$ & $\begin{array}{c}\text { High } \\
\text { Si } \\
10 \%\end{array}$ & $\begin{array}{c}\text { High } \\
\mathrm{Si} \\
10 \%\end{array}$ & $\begin{array}{l}\text { Peat } \\
\text { Con- } \\
\text { trol }\end{array}$ & $\begin{array}{l}\text { Peat } \\
\text { Con- } \\
\text { trol }\end{array}$ \\
\hline Time & I & Beg. & End & Beg. & End & Beg. & End & Beg. & End & Beg. & End & Beg. & End & Beg. & End \\
\hline $\begin{array}{l}\text { Low } \\
\text { P Si } \\
0 \%\end{array}$ & Beg. & / & 0.2391 & 0.1439 & 0.0041 & 0.0004 & 0.2017 & $\begin{array}{c}2.264 \\
\times \\
10^{-6}\end{array}$ & 0.0005 & $\begin{array}{c}3.784 \\
\times \\
10^{-8}\end{array}$ & $\begin{array}{c}4.255 \\
\times \\
10^{-6}\end{array}$ & $\begin{array}{c}7.262 \\
\times \\
10^{-8}\end{array}$ & $\begin{array}{c}4.923 \\
\times \\
10^{-6}\end{array}$ & $\begin{array}{c}7.918 \\
\times \\
10^{-5}\end{array}$ & $\begin{array}{c}5.355 \\
\times \\
10^{-5}\end{array}$ \\
\hline $\begin{array}{l}\text { Low } \\
\text { P Si } \\
0 \%\end{array}$ & End & & / & / & 0.0130 & / & 0.0303 & / & $\begin{array}{c}7.772 \\
\times \\
10^{-5}\end{array}$ & / & $\begin{array}{c}3.711 \\
\times \\
10^{-7}\end{array}$ & / & $\begin{array}{c}1.483 \\
\times \\
10^{-6}\end{array}$ & / & $\begin{array}{c}2.116 \\
\times \\
10^{-5}\end{array}$ \\
\hline $\begin{array}{l}\text { Low } \\
\text { P Si } \\
1 \%\end{array}$ & Beg. & & & / & 0.0384 & $\begin{array}{c}2.491 \\
\times \\
10^{-5}\end{array}$ & 0.022 & $\begin{array}{c}2.381 \\
\times \\
10^{-7}\end{array}$ & $\begin{array}{c}7.704 \\
\times \\
10^{-5}\end{array}$ & $\begin{array}{c}4.039 \\
\times \\
10^{-9}\end{array}$ & $\begin{array}{c}3.837 \\
\times \\
10^{-7}\end{array}$ & $\begin{array}{c}2.29 \\
\times \\
10^{-8}\end{array}$ & $\begin{array}{c}1.372 \\
\times \\
10^{-6}\end{array}$ & $\begin{array}{c}5.248 \\
\times \\
10^{-5}\end{array}$ & $\begin{array}{c}3.143 \\
\times \\
10^{-5}\end{array}$ \\
\hline $\begin{array}{l}\text { Low } \\
\text { P Si } \\
1 \%\end{array}$ & End & & & & / & / & 0.0010 & / & $\begin{array}{c}3.48 \\
\times \\
10^{-6}\end{array}$ & / & $\begin{array}{c}7.562 \\
\times \\
10^{-9}\end{array}$ & / & $\begin{array}{c}4.758 \\
\times \\
10^{-8}\end{array}$ & / & $\begin{array}{c}5.55 \\
\times \\
10^{-7}\end{array}$ \\
\hline $\begin{array}{l}\text { Low } \\
\text { P Si } \\
10 \%\end{array}$ & Beg. & & & & & / & 0.0144 & $\begin{array}{c}6.628 \\
\times \\
10^{-5}\end{array}$ & 0.0341 & $\begin{array}{c}8.207 \\
\times \\
10^{-8}\end{array}$ & 0.0002 & $\begin{array}{c}2.486 \\
\times \\
10^{-7}\end{array}$ & $\begin{array}{c}7.605 \\
\times \\
10^{-5}\end{array}$ & $\begin{array}{c}4.431 \\
\times \\
10^{-6}\end{array}$ & $\begin{array}{c}2.576 \\
\times \\
10^{-6}\end{array}$ \\
\hline $\begin{array}{l}\text { Low } \\
\text { P Si } \\
10 \%\end{array}$ & End & & & & & & / & / & 0.0100 & / & 0.0712 & / & 0.0061 & I & 0.0013 \\
\hline $\begin{array}{c}\text { High } \\
\text { P Si } \\
0 \%\end{array}$ & Beg. & & & & & & & / & 0.0159 & 0.0003 & 0.1461 & $\begin{array}{c}3.799 \\
\times \\
10^{-6}\end{array}$ & 0.0254 & $\begin{array}{c}1.063 \\
\times \\
10^{-6}\end{array}$ & $\begin{array}{c}5.663 \\
\times \\
10^{-7}\end{array}$ \\
\hline $\begin{array}{c}\text { High } \\
\text { P Si } \\
0 \%\end{array}$ & End & & & & & & & & / & / & 0.0712 & / & 0.0061 & I & 0.0013 \\
\hline $\begin{array}{c}\text { High } \\
\text { P Si } \\
1 \%\end{array}$ & Beg. & & & & & & & & & / & $\begin{array}{c}1.409 \\
\times \\
10^{-6}\end{array}$ & 0.0003 & 0.1128 & $\begin{array}{c}7.13 \\
\times \\
10^{-8}\end{array}$ & $\begin{array}{c}1.599 \\
\times \\
10^{-8}\end{array}$ \\
\hline $\begin{array}{c}\text { High } \\
\text { P Si } \\
1 \%\end{array}$ & End & & & & & & & & & & / & I & 0.0041 & / & $\begin{array}{c}4.54 \\
\times \\
10^{-7}\end{array}$ \\
\hline
\end{tabular}


Table A4. Cont.

\begin{tabular}{|c|c|c|c|c|c|c|c|c|c|c|c|c|c|c|c|}
\hline $\mathbf{P}$ & Time & $\begin{array}{l}\text { Low } \\
\text { P Si } \\
0 \%\end{array}$ & $\begin{array}{c}\text { Low } \\
\text { P Si } \\
0 \%\end{array}$ & $\begin{array}{c}\text { Low } \\
\text { P Si } \\
1 \%\end{array}$ & $\begin{array}{l}\text { Low } \\
\text { P Si } \\
1 \%\end{array}$ & $\begin{array}{l}\text { Low } \\
\text { P Si } \\
10 \%\end{array}$ & $\begin{array}{l}\text { Low } \\
\text { P Si } \\
10 \%\end{array}$ & $\begin{array}{c}\text { High } \\
\text { P Si } \\
0 \%\end{array}$ & $\begin{array}{c}\text { High } \\
\text { P Si } \\
0 \%\end{array}$ & $\begin{array}{c}\text { High } \\
\text { P Si } \\
1 \%\end{array}$ & $\begin{array}{c}\text { High } \\
\text { P Si } \\
1 \%\end{array}$ & $\begin{array}{c}\text { High } \\
\text { Si } \\
10 \%\end{array}$ & $\begin{array}{c}\text { High } \\
\text { Si } \\
10 \%\end{array}$ & $\begin{array}{l}\text { Peat } \\
\text { Con- } \\
\text { trol }\end{array}$ & $\begin{array}{l}\text { Peat } \\
\text { Con- } \\
\text { trol }\end{array}$ \\
\hline Time & 1 & Beg. & End & Beg. & End & Beg. & End & Beg. & End & Beg. & End & Beg. & End & Beg. & End \\
\hline $\begin{array}{c}\text { High } \\
\text { P Si } \\
10 \%\end{array}$ & Beg. & & & & & & & & & & & / & 0.0005 & $\begin{array}{c}3.144 \\
\times \\
10^{-6}\end{array}$ & $\begin{array}{c}2.541 \\
\times \\
10^{-6}\end{array}$ \\
\hline $\begin{array}{c}\text { High } \\
\text { P Si } \\
10 \%\end{array}$ & End & & & & & & & & & & & & / & I & $\begin{array}{c}1.361 \\
\times \\
10^{-5}\end{array}$ \\
\hline $\begin{array}{l}\text { Peat } \\
\text { Con- } \\
\text { trol }\end{array}$ & Beg. & & & & & & & & & & & & & / & 0.0001 \\
\hline TOC & Time & $\begin{array}{l}\text { Low } \\
\text { P Si } \\
0 \%\end{array}$ & $\begin{array}{c}\text { Low } \\
\text { P Si } \\
0 \%\end{array}$ & $\begin{array}{c}\text { Low } \\
\text { P Si } \\
1 \%\end{array}$ & $\begin{array}{l}\text { Low } \\
\text { P Si } \\
1 \%\end{array}$ & $\begin{array}{l}\text { Low } \\
\text { P Si } \\
10 \%\end{array}$ & $\begin{array}{l}\text { Low } \\
\text { P Si } \\
10 \%\end{array}$ & $\begin{array}{c}\text { High } \\
\text { P Si } \\
0 \%\end{array}$ & $\begin{array}{c}\text { High } \\
\text { P Si } \\
0 \%\end{array}$ & $\begin{array}{c}\text { High } \\
\text { P Si } \\
1 \%\end{array}$ & $\begin{array}{c}\text { High } \\
\text { P Si } \\
1 \%\end{array}$ & $\begin{array}{c}\text { High } \\
\text { Si } \\
10 \%\end{array}$ & $\begin{array}{c}\text { High } \\
\text { Si } \\
10 \%\end{array}$ & $\begin{array}{l}\text { Peat } \\
\text { Con- } \\
\text { trol }\end{array}$ & $\begin{array}{l}\text { Peat } \\
\text { Con- } \\
\text { trol }\end{array}$ \\
\hline Time & 1 & Beg. & End & Beg. & End & Beg. & End & Beg. & End & Beg. & End & Beg. & End & Beg. & End \\
\hline $\begin{array}{l}\text { Low } \\
\text { P Si } \\
0 \%\end{array}$ & Beg. & / & 0.0036 & $\begin{array}{c}8.157 \\
\times \\
10^{-7}\end{array}$ & $\begin{array}{c}1.676 \\
\times \\
10^{-5}\end{array}$ & 0.0002 & $\begin{array}{c}4.849 \\
\times \\
10^{-7}\end{array}$ & 0.0521 & $\begin{array}{c}5.752 \\
\times \\
10^{-7}\end{array}$ & 0.0023 & 0.0020 & 0.0005 & $\begin{array}{c}6.707 \\
\times \\
10^{-8}\end{array}$ & $\begin{array}{c}2.631 \\
\times \\
10^{-7}\end{array}$ & $\begin{array}{c}1.614 \\
\times \\
10^{-7}\end{array}$ \\
\hline $\begin{array}{c}\text { Low } \\
\text { P Si } \\
0 \%\end{array}$ & End & & / & I & 0.1042 & / & 0.5271 & / & 0.2313 & I & 0.3314 & / & 0.3161 & / & 0.0002 \\
\hline $\begin{array}{l}\text { Low } \\
\text { P Si } \\
1 \%\end{array}$ & Beg. & & & / & 0.0076 & 0.0230 & 0.0014 & 0.0007 & 0.0664 & $\begin{array}{c}7.158 \\
\times \\
10^{-5}\end{array}$ & 0.0395 & 0.6043 & $\begin{array}{c}3.678 \\
\times \\
10^{-6}\end{array}$ & $\begin{array}{c}7.508 \\
\times \\
10^{-9}\end{array}$ & $\begin{array}{c}6.019 \\
\times \\
10^{-15}\end{array}$ \\
\hline $\begin{array}{l}\text { Low } \\
\text { P Si } \\
1 \%\end{array}$ & End & & & & / & / & 0.09877 & / & 0.0100 & / & 0.5478 & / & 0.2217 & / & 0.0002 \\
\hline $\begin{array}{l}\text { Low } \\
\text { P Si } \\
10 \%\end{array}$ & Beg. & & & & & / & $\begin{array}{c}6.669 \\
\times \\
10^{-5}\end{array}$ & 0.0002 & 0.0030 & 0.0382 & 0.0130 & 0.0850 & $\begin{array}{c}9.045 \\
\times \\
10^{-6}\end{array}$ & $\begin{array}{c}1.085 \\
\times \\
10^{-6}\end{array}$ & $\begin{array}{c}7.892 \\
\times \\
10^{-7}\end{array}$ \\
\hline $\begin{array}{l}\text { Low } \\
\text { P Si } \\
10 \%\end{array}$ & End & & & & & & / & / & 0.0004 & / & 0.5011 & / & 0.3025 & / & $\begin{array}{c}2.692 \\
\times \\
10^{-6}\end{array}$ \\
\hline $\begin{array}{c}\text { High } \\
\text { P Si } \\
0 \%\end{array}$ & Beg. & & & & & & & / & 0.0005 & 0.0012 & 0.0001 & 0.0002 & $\begin{array}{c}1.158 \\
\times \\
10^{-6}\end{array}$ & $\begin{array}{c}4.445 \\
\times \\
10^{-6}\end{array}$ & $\begin{array}{c}3.984 \\
\times \\
10^{-6}\end{array}$ \\
\hline $\begin{array}{c}\text { High } \\
\text { P Si } \\
0 \%\end{array}$ & End & & & & & & & & / & / & 0.0538 & / & $\begin{array}{c}1.27 \\
\times \\
10^{-5}\end{array}$ & I & $\begin{array}{c}2.169 \\
\times \\
10^{-9}\end{array}$ \\
\hline $\begin{array}{c}\text { High } \\
\text { P Si } \\
1 \% \\
\end{array}$ & Beg. & & & & & & & & & / & 0.0012 & 0.0092 & $\begin{array}{c}7.252 \\
\times \\
10^{-7} \\
\end{array}$ & $\begin{array}{c}4.377 \\
\times \\
10^{-7} \\
\end{array}$ & $\begin{array}{c}2.795 \\
\times \\
10^{-7} \\
\end{array}$ \\
\hline $\begin{array}{c}\text { High } \\
\text { P Si } \\
1 \%\end{array}$ & End & & & & & & & & & & / & / & 0.0538 & / & $\begin{array}{c}1.27 \\
\times \\
10^{-5}\end{array}$ \\
\hline $\begin{array}{c}\text { High } \\
\text { P Si } \\
10 \%\end{array}$ & Beg. & & & & & & & & & & & / & 0.0105 & $\begin{array}{c}3.64 \\
\times \\
10^{-5}\end{array}$ & $\begin{array}{c}3.326 \\
\times \\
10^{-5}\end{array}$ \\
\hline $\begin{array}{c}\text { High } \\
\text { P Si } \\
10 \%\end{array}$ & End & & & & & & & & & & & & / & I & $\begin{array}{c}2.169 \\
\times \\
10^{-9}\end{array}$ \\
\hline $\begin{array}{l}\text { Peat } \\
\text { Con- } \\
\text { trol }\end{array}$ & Beg. & & & & & & & & & & & & & I & 0.0072 \\
\hline $\begin{array}{l}\text { Peat } \\
\text { Con- } \\
\text { trol }\end{array}$ & End & & & & & & & & & & & & & & / \\
\hline
\end{tabular}


Table A4. Cont.

\begin{tabular}{|c|c|c|c|c|c|c|c|c|c|c|c|c|c|c|c|}
\hline $\mathrm{Fe}$ & Time & $\begin{array}{c}\text { Low } \\
\text { P Si } \\
0 \%\end{array}$ & $\begin{array}{c}\text { Low } \\
\text { P Si } \\
0 \%\end{array}$ & $\begin{array}{l}\text { Low } \\
\text { P Si } \\
1 \%\end{array}$ & $\begin{array}{l}\text { Low } \\
\text { P Si } \\
1 \%\end{array}$ & $\begin{array}{l}\text { Low } \\
\text { P Si } \\
10 \%\end{array}$ & $\begin{array}{l}\text { Low } \\
\text { P Si } \\
10 \%\end{array}$ & $\begin{array}{c}\text { High } \\
\text { P Si } \\
0 \%\end{array}$ & $\begin{array}{c}\text { High } \\
\text { P Si } \\
0 \%\end{array}$ & $\begin{array}{c}\text { High } \\
\text { P Si } \\
1 \%\end{array}$ & $\begin{array}{c}\text { High } \\
\text { P Si } \\
1 \%\end{array}$ & $\begin{array}{l}\text { High } \\
\text { Si } \\
10 \%\end{array}$ & $\begin{array}{c}\text { High } \\
\text { Si } \\
10 \%\end{array}$ & $\begin{array}{l}\text { Peat } \\
\text { Con- } \\
\text { trol }\end{array}$ & $\begin{array}{l}\text { Peat } \\
\text { Con- } \\
\text { trol }\end{array}$ \\
\hline Time & I & Beg. & End & Beg. & End & Beg. & End & Beg. & End & Beg. & End & Beg. & End & Beg. & End \\
\hline $\begin{array}{c}\text { Low } \\
\text { P Si } \\
0 \%\end{array}$ & Beg. & / & $\begin{array}{c}2.224 \\
\times \\
10^{-7}\end{array}$ & 0.1022 & $\begin{array}{c}4.575 \\
\times \\
10^{-6}\end{array}$ & $\begin{array}{c}7.101 \\
\times \\
10^{-6}\end{array}$ & 0.0102 & 0.0543 & $\begin{array}{c}1.448 \\
\times \\
10^{-5}\end{array}$ & $\begin{array}{c}3.548 \\
\times \\
10^{-5}\end{array}$ & 0.0009 & 0.0009 & 0.0661 & $\begin{array}{c}8.41 \\
\times \\
10^{-6}\end{array}$ & $\begin{array}{c}2.443 \\
\times \\
10^{-5}\end{array}$ \\
\hline $\begin{array}{c}\text { Low } \\
\text { P Si } \\
0 \%\end{array}$ & End & & / & / & 0.0026 & / & 0.0005 & / & 0.0038 & / & $\begin{array}{c}6.122 \\
\times \\
10^{-6}\end{array}$ & / & $\begin{array}{c}2.474 \\
\times \\
10^{-6}\end{array}$ & / & $\begin{array}{c}1.099 \\
\times \\
10^{-5}\end{array}$ \\
\hline $\begin{array}{c}\text { Low } \\
\text { P Si } \\
1 \%\end{array}$ & Beg. & & & / & $\begin{array}{c}4.577 \\
\times \\
10^{-6}\end{array}$ & 0.0003 & 0.0056 & 0.7684 & $\begin{array}{c}3.62 \\
\times \\
10^{-5}\end{array}$ & 0.0014 & 0.0004 & 0.0067 & 0.0124 & 0.0001 & 0.0004 \\
\hline $\begin{array}{c}\text { Low } \\
\text { P Si } \\
1 \%\end{array}$ & End & & & & / & / & 0.0115 & / & 0.6255 & / & 0.0004 & / & $\begin{array}{c}8.033 \\
\times \\
10^{-5}\end{array}$ & / & $\begin{array}{c}2.649 \\
\times \\
10^{-5}\end{array}$ \\
\hline $\begin{array}{l}\text { Low } \\
\text { P Si } \\
10 \%\end{array}$ & Beg. & & & & & / & 0.0002 & 0.0004 & $\begin{array}{c}1.249 \\
\times \\
10^{-6}\end{array}$ & 0.3265 & $\begin{array}{c}1.739 \\
\times \\
10^{-6}\end{array}$ & 0.9748 & $\begin{array}{c}2.068 \\
\times \\
10^{-5}\end{array}$ & 0.0003 & 0.0044 \\
\hline $\begin{array}{l}\text { Low } \\
\text { P Si } \\
10 \%\end{array}$ & End & & & & & & / & / & 0.0401 & / & 0.6997 & / & 0.1221 & / & 0.0133 \\
\hline $\begin{array}{c}\text { High } \\
\text { P Si } \\
0 \%\end{array}$ & Beg. & & & & & & & / & $\begin{array}{c}2.822 \\
\times \\
10^{-5}\end{array}$ & 0.0019 & 0.0003 & 0.0089 & 0.0078 & 0.0001 & 0.0004 \\
\hline $\begin{array}{c}\text { High } \\
\text { P Si } \\
0 \%\end{array}$ & End & & & & & & & & / & / & 0.0017 & / & 0.0005 & / & 0.0018 \\
\hline $\begin{array}{c}\text { High } \\
\text { P Si } \\
1 \%\end{array}$ & Beg. & & & & & & & & & / & $\begin{array}{c}4.484 \\
\times \\
10^{-6}\end{array}$ & 0.595 & $\begin{array}{c}5.616 \\
\times \\
10^{-5}\end{array}$ & 0.0003 & 0.0032 \\
\hline $\begin{array}{c}\text { High } \\
\text { P Si } \\
1 \%\end{array}$ & End & & & & & & & & & & / & / & 0.0695 & / & $\begin{array}{c}5.02 \\
\times \\
10^{-5}\end{array}$ \\
\hline $\begin{array}{l}\text { High } \\
\text { P Si } \\
10 \%\end{array}$ & Beg. & & & & & & & & & & & / & 0.0004 & 0.0091 & 0.0769 \\
\hline $\begin{array}{l}\text { High } \\
\text { P Si } \\
10 \%\end{array}$ & End & & & & & & & & & & & & / & / & 0.0002 \\
\hline $\begin{array}{l}\text { Peat } \\
\text { Con- } \\
\text { trol }\end{array}$ & Beg. & & & & & & & & & & & & & / & $\begin{array}{c}3.663 \\
\times \\
10^{-9}\end{array}$ \\
\hline $\begin{array}{l}\text { Peat } \\
\text { Con- } \\
\text { trol }\end{array}$ & End & & & & & & & & & & & & & & / \\
\hline
\end{tabular}

The typesetting of the $p$-values indicated the test in $\mathrm{R}$ used for calculation: normal typesetting $=t$ test; italic typesetting $=$ welch.test; underlined typesetting = wilcox.test. 


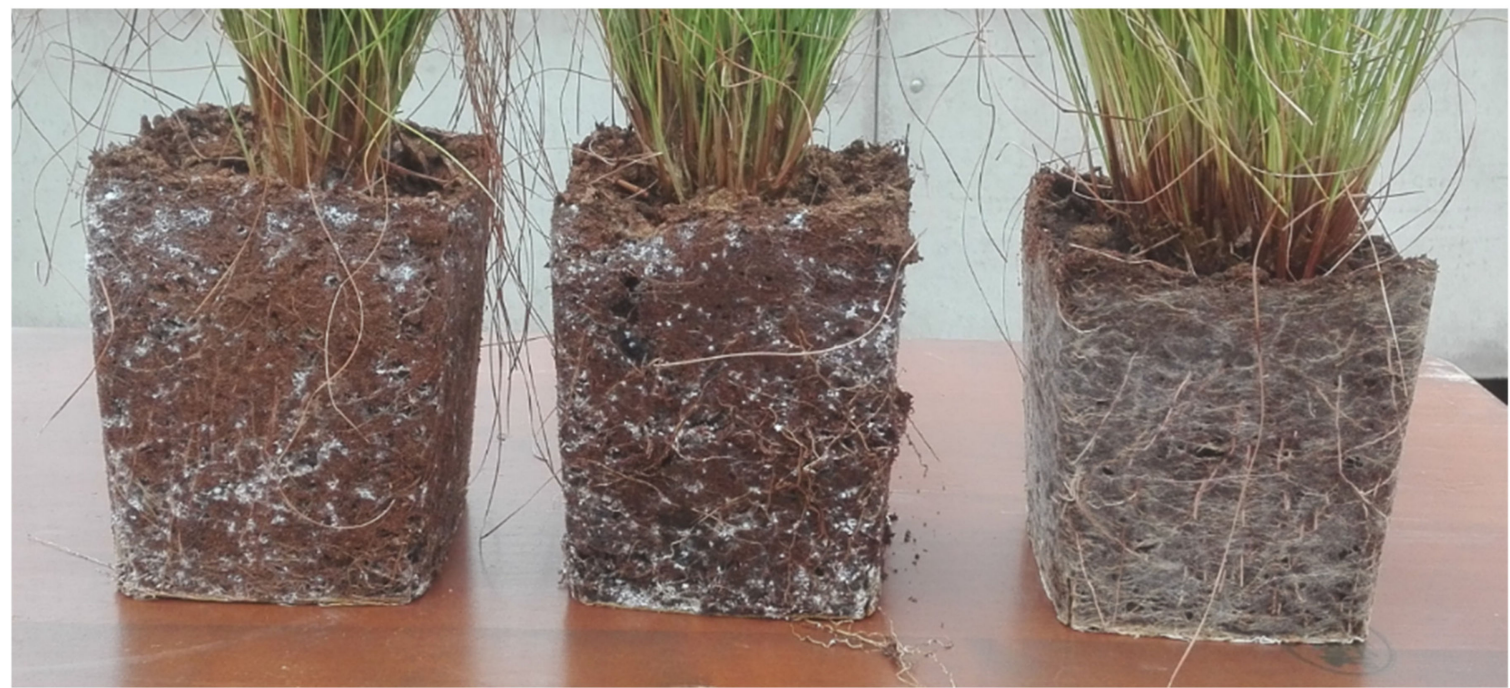

Figure A1. Soil of the Eriophorum plants prior to harvest. Left side: substrate contains $0 \% \mathrm{SiO}_{2}$, Middle: substrate contains $1 \% \mathrm{SiO}_{2}$, Right side, substrate contains $10 \% \mathrm{Si}$. White points in the left and middle sample are root aphids (Rhizoecus ssp.). The Si $10 \%$ treatment showed no infestation. 

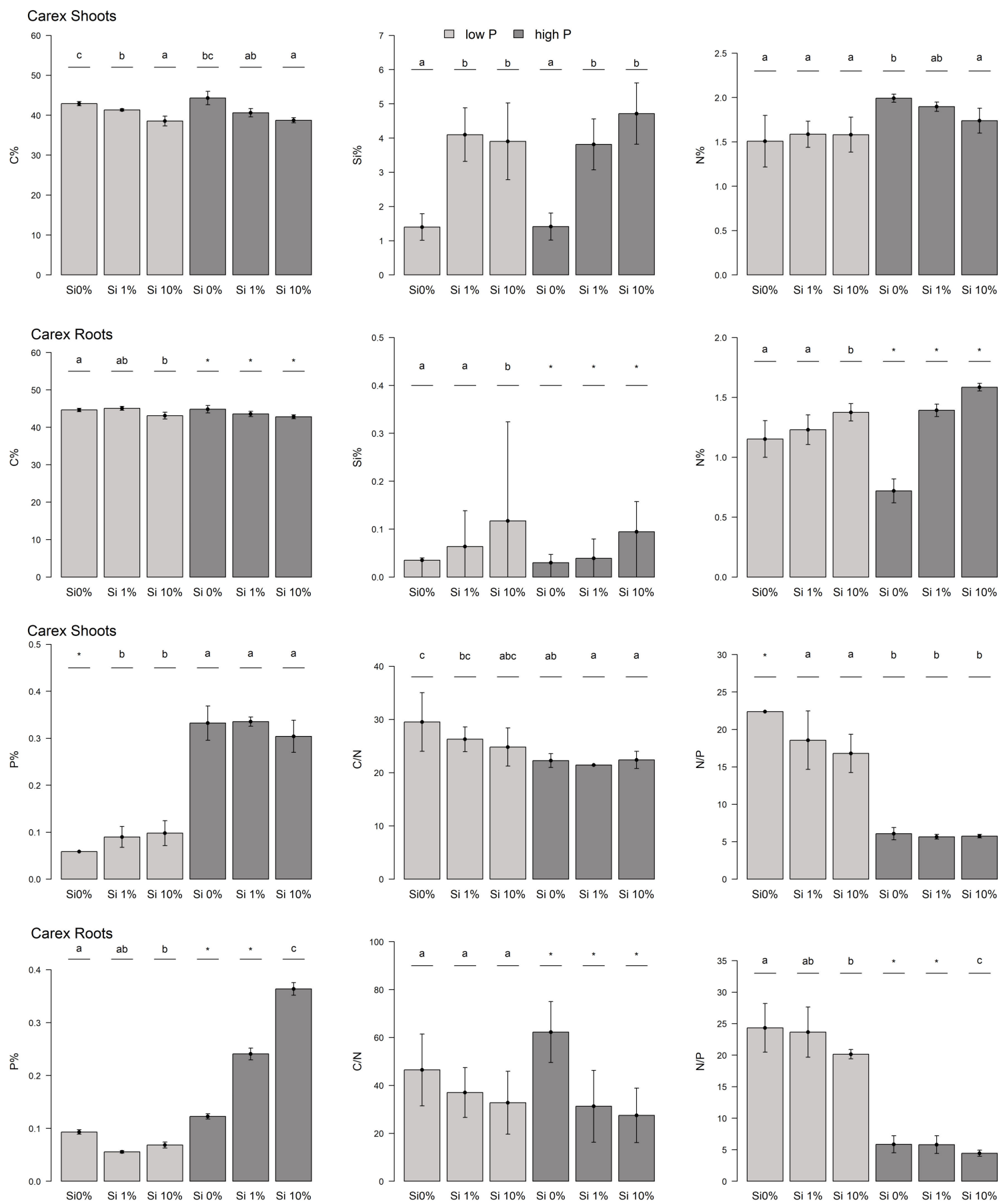

Figure A2. Carex aboveground and belowground biomass. Contents of $\mathrm{C}, \mathrm{Si}, \mathrm{N}$ as well as $\mathrm{P}$ and the $\mathrm{C} / \mathrm{N}$ and $\mathrm{N} / \mathrm{P}$ ratios are displayed. Low P fertilized plants: light gray, high P fertilized plants: dark gray. Different letters give significant differences between the treatments $(\alpha=0.05)$, those treatments that are marked with an asterisk $\left({ }^{*}\right)$ have too few data for statistical evaluation. 


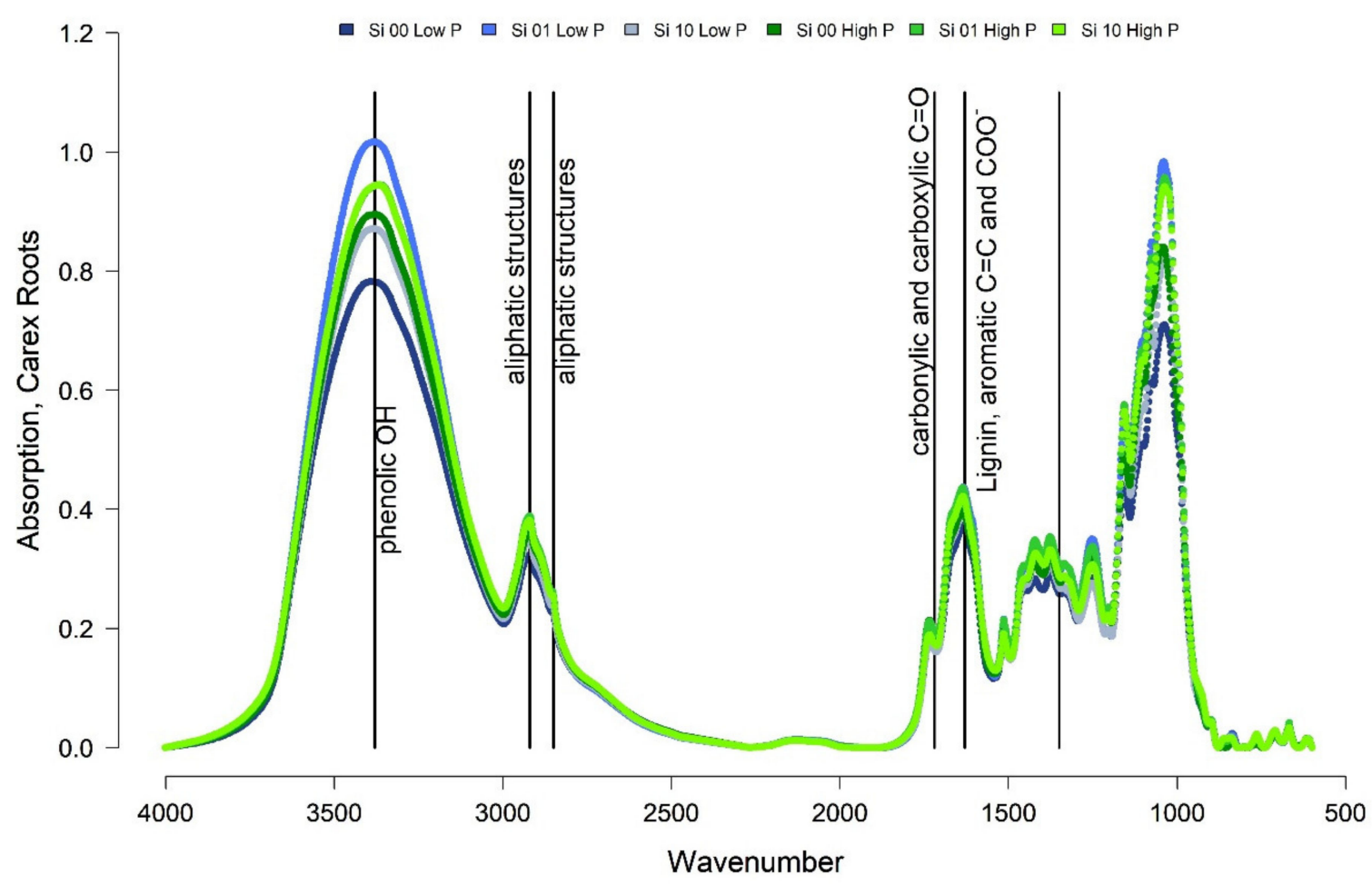

Figure A3. FTIR Spectra of Carex roots before the incubation. Low P fertilized plants are shown in blue, high P fertilized plants are shown in green.

\section{References}

1. Yu, Z.; Loisel, J.; Brosseau, D.P.; Beilman, D.W.; Hunt, S.J. Global peatland dynamics since the Last Glacial Maximum. Geophys. Res. Lett. 2010, 37. [CrossRef]

2. Aselmann, I.; Crutzen, P.J. Global Distribution of Natural Freshwater Wetlands and Rice Paddies, their Net Primary Productivity, Seasonality and Possible Methane Emissions. J. Atmos. Chem. 1989, 8, 307-358. [CrossRef]

3. Clymo, R.S. The Limits of peat bog growth. Philos. Trans. R. Soc. Lond. B Biol. Sci. 1984, 303, 605-654.

4. Limpens, J.; Berendse, F.; Blodau, C.; Canadell, J.G.; Freeman, C.; Holden, J.; Roulet, N.; Rydin, H.; Schaepman-Strub, G. Peatlands and the carbon cycle: From local processes to global implications-A synthesis. Biogeosciences 2008, 5, 1475-1491. [CrossRef]

5. Rydin, H.; Jeglum, J.K. The Biology of Peatlands; Oxford Scholarship Online: Oxford, UK, 2006.

6. Aerts, R.; De Caluwe, H. Nutritional and Plant-Mediated Controls on Leaf Litter Decomposition of Carex Species. Ecology 1997, 78, 255-260. [CrossRef]

7. Agethen, S.; Knorr, K.-H. Juncus effusus mono-stands in restored cutover peat bogs-Analysis of litter quality, controls of anaerobic decomposition, and the risk of secondary carbon loss. Soil Biol. Biochem. 2018, 117, 139-152. [CrossRef]

8. McClaugherty, C.; Berg, B. Cellulose, lignin and nitrogen concentrations as rate regulating factors in late stages of forest litter decomposition. Pedobiologia 1987, 30, 101-112.

9. Epstein, E. The anomaly of silicon in plant biology. Proc. Natl. Acad. Sci. USA 1994, 91, 11-17. [CrossRef] [PubMed]

10. Katz, O. Beyond grasses: The potential benefits of studying silicon accumulation in non-grass species. Front. Plant Sci. 2014, 5, 376. [CrossRef] [PubMed]

11. Schaller, J.; Heimes, R.; Ma, J.F.; Meunier, J.-D.; Shao, J.F.; Fujii-Kashino, M.; Knorr, K.H. Silicon accumulation in rice plant aboveground biomass affects leaf carbon quality. Plant. Soil 2019, 444, 399-407. [CrossRef]

12. Schaller, J.; Struyf, E. Silicon controls microbial decay and nutrient release of grass litter during aquatic decomposition. Hydrobiologica 2013, 709, 201-212. [CrossRef]

13. Wainwright, M.; Al-Wajeeh, K.; Grayston, S.J. Effect of silicic acid and other silicon compounds on fungal growth in oligotrophic and nutrient-rich media. Mycol. Res. 1997, 101, 933-938. [CrossRef]

14. Reithmaier, G.-M.; Knorr, K.-H.; Arnhold, S.; Planer-Friedrich, B.; Schaller, J. Enhanced silicon availability leads to increased methane production, nutrient and toxicant mobility in peatlands. Sci. Rep. 2017, 7, 8728. [CrossRef]

15. Broder, T.; Blodau, C.; Biester, H.; Knorr, K.H. Peat decomposition records in three pristine ombrotrophic bogs in southern Patagonia. Biogeosciences 2012, 9, 1479-1491. [CrossRef]

16. Niemeyer, J.; Chen, Y.; Bollag, J.-M. Characterization of Humic Acids, Composts, and Peat by Diffuse Reflectance FourierTransform Infrared Spectroscopy. J. Soil Sci. Soc. Am. 1992, 56, 135-140. [CrossRef] 
17. Klotzbücher, T.; Klotzbücher, A.; Kaiser, K.; Vetterlein, D.; Jahn, R.; Mikutta, R. Variable silicon accumulation in plants affects terrestrial carbon cycling by controlling lignin synthesis. Glob. Chang. Biol. 2018, 24, e183-e189. [CrossRef] [PubMed]

18. Currie, H.A.; Perry, C.C. Silica in plants: Biological, biochemical and chemical studies. Ann. Bot. 2007, 100, 1383-1389. [CrossRef]

19. Neu, S.; Schaller, J.; Dudel, E.G. Silicon availability modifies nutrient use efficiency and content, C:N:P stoichiometry, and productivity of winter wheat (Triticum aestivum L.). Sci. Rep. 2017, 7, 40829. [CrossRef]

20. Schaller, J.; Brackhage, C.; Gessner, M.O.; Bäuker, E.; Dudel, E.G. Silicon supply modifies C:N:P stoichiometry and growth of Phragmites australis. Plant Biol. 2012, 14, 392-396. [CrossRef] [PubMed]

21. Scheffer, R.A.; Aerts, R. Root decomposition and soil nutrient and carbon cycling in two temperate fen ecosystems. OIKOS 2000, 91, 541-549. [CrossRef]

22. Schoelynck, J.; Bal, K.; Backx, H.; Okruszko, T.; Meire, P.; Struyf, E. Silica uptake in aquatic and wetland macrophytes: A strategic choice between silica, lignin ans cellulose ? New Phytol. 2010, 186, 385-391. [CrossRef]

23. Schaller, J.; Brackhage, C.; Dudel, E.G. Silicon availability changes structural carbon ratio and phenol content of grasses. Environ. Exp. Bot. 2012, 77, 283-287. [CrossRef]

24. Ma, J.F. Role of silicon in enhancing the resistance of plants to biotic and abiotic stresses. Soil Sci. Plant Nutr. 2004, 50, 11-18. [CrossRef]

25. Gao, C.; Sander, M.; Agethen, S.; Knorr, K.H. Electron accepting capacity of dissolved and particulate organic matter control CO2 and CH4 formation in peat soils. Geochim. Cosmochim. Acta 2019, 245, 266-277. [CrossRef]

26. Hömberg, A.; Broder, T.; Knorr, K.H.; Schaller, J. Divergent effect of silicon on greenhouse gas production from reduced and oxidized peat organic matter. Geoderma 2021, 386. [CrossRef]

27. Fedorak, P.M.; Hrudey, S.E. The effects of phenol and some alkyl phenolics on batch anaerobic methanogenesis. Water Res. 1984, 18, 361-367. [CrossRef]

28. Kuiters, A.T. Role of phenolic substances from decomposing forest litter in plant-soil interactions. Acta Bor. Neerl. 1990, 39, 329-348. [CrossRef]

29. Mastný, J.; Kaštovská, E.; Bárta, J.; Chroňáková, A.; Borovec, J.; Šantrůčková, H.; Urbanová, Z.; Edwards, K.R.; Picek, T. Quality of DOC produced during litter decomposition of peatland plant dominants. Soil Biol. Biochem. 2018, 121, 221-230. [CrossRef]

30. Struyf, E.; Van Damme, S.; Gribsholt, B.; Bal, K.; Beauchard, O.; Middelburg, J.J.; Meire, P. Phragmites australis and silica cycling in tidal wetlands. Aquat. Bot. 2007, 87, 134-140. [CrossRef]

31. Matichenkov, V.V.; Calvert, D.V. Silicon as a Beneficial Element for Sugarcane. J. Am. Soc. Sugar Cane Technol. 2002, $22,21-29$.

32. Schaller, J.; Faucherre, S.; Joss, H.; Obst, M.; Goeckede, M.; Planer-Friedrich, B.; Peiffer, S.; Gilfedder, B.; Elberling, B. Silicon increases the phosphorus availability of Arctic soils. Sci. Rep. 2019, 9, 449. [CrossRef] [PubMed]

33. Hömberg, A.; Obst, M.; Knorr, K.-H.; Kalbitz, K.; Schaller, J. Increased silicon concentration in fen peat leads to a release of iron and phosphate and changes in the composition of dissolved organic matter. Geoderma 2020, 374. [CrossRef]

34. Schaller, J.; Puppe, D.; Kaczorek, D.; Ellerbrock, R.; Sommer, M. Review. Silicon cycling in soils revisited. Plants 2021, 10, 295. [CrossRef]

35. Matzner, E.; Berg, B. Effect of $\mathrm{N}$ deposition on decomposition of plant litter and soil organic matter in forest systems. Environ. Rev. 1997, 5, 1-25.

36. Voronin, P.Y.; Mukhin, V.A. Methane emission during wood fungal decomposition. Dokl. Biol. Sci. 2007, 413, 159-160. [CrossRef]

37. Knorr, K.-H.; Lischeid, G.; Blodau, C. Dynamics of redox processes in a minerotrophic fen exposed to a water table manipulation. Geoderma 2009, 153, 379-392. [CrossRef]

38. Paul, S.; Kusel, K.; Alewell, C. Reduction processes in forest wetlands: Tracking down heterogeneity of source/sink functions with a combination of methods. Soil Biol. Biochem. 2006, 38, 1028-1039. [CrossRef]

39. Goldberg, S.D.; Knorr, K.-H.; Gebauer, G. $\mathrm{N}_{2} \mathrm{O}$ concentration and isotope signature along profiles provide deeper insight into the fate of $\mathrm{N}_{2} \mathrm{O}$ in soils. Isot. Environ. Health Stud. 2008, 44, 377-391. [CrossRef]

40. Meunier, J.D.; Keller, C.; Guntzer, F.; Riotte, J.; Braun, J.J.; Anupama, K. Assessment of the $1 \% \mathrm{Na}_{2} \mathrm{CO}_{3}$ technique to quantify the phytolith pool. Geoderma 2014, 216, 30-35. [CrossRef]

41. Swedish_Standards_Institute. DIN EN 13805:2002 Foodstuffs—Determination of Trace Elements—Pressure Digestion. 2002. Available online: https:/ / www.sis.se/en/produkter/food-technology/general-methods-of-tests-and-analysis-for-food-products / ssen13805/ (accessed on 12 February 2018).

42. R-Core-Team. R: A Language and Environment for Statistical Computing, R Version 3.5.2. 2019. Available online: https: / / www.R-project.org/ (accessed on 2 December 2019).

43. Teickner, H. ir: A Simple Package to Handle and Preprocess Infrared Spectra. R Package Version 0.0.0.9000, 0.0.0.9000. 2020. Available online: https:/ / github.com/henningte/ir (accessed on 6 July 2020).

44. Beleites, C.; Sergo, V. hyperSpec: A Package to Handle Hyperspectral Data Sets in R. R Package Version 0.99-20200527, 0.9920200213.1. 2020. Available online: https:/ / github.com/cbeleites/hyperSpec (accessed on 3 December 2019).

45. Harrell, F.E. Hmisc: Harrell Miscellaneous. R Package., 4.2-0. 2019. Available online: https://github.com/harrelfe/Hmisc/ (accessed on 3 December 2019). 